\title{
Convergence and fixed point theorems in convex metric spaces : a survey
}

\author{
Renu Chugh, Preety Malik* \\ Department of Mathematics, Maharshi Dayanand University, Rohtak-124001, India \\ *Corresponding author E-mail: preety0709@gmail.com
}

Copyright $\odot 2014$ Renu Chugh, Preety Malik. This is an open access article distributed under the Creative Commons Attribution License, which permits unrestricted use, distribution, and reproduction in any medium, provided the original work is properly cited.

\begin{abstract}
The aim of this paper is to provide a survey of the fixed point theorems, convergence theorems and stability results of iterative schemes that have been studied by many authors in convex metric spaces. This paper should be a useful reference for those persons wishing to become better acquainted with the area.
\end{abstract}

Keywords: Convex Metric Spaces, Fixed Point, Hyperbolic Spaces, Iterative Schemes, Stability.

\section{Introduction}

There are many metric structures which have called the attention of a large number of mathematicians from different branches. These structures include hyper convex metric spaces, convex metric space and hyperbolic spaces. All of them have shown to be good structures to develop analysis from different perspectives. Convex metric spaces as well as hyperconvex spaces may also be considered within this class of intriguing metric structures which allow us to obtain results which one would only expect to be possible under certain linear structures.

The present paper contains several results proved by many authors in convex metric spaces. In section 2 , we give various definitions which are used in the results. Section 3, contains various fixed point theorems proved in convex metric spaces. In section 4, we present the results studied on the convergence of fixed point iterative schemes in convex metric spaces. In the next section we study the results in hyperbolic spaces introduced by Kohlenbach [68].

The notion of convexity in metric spaces was introduced by Takahashi [78] and he established that all normed spaces and their convex subsets are convex metric spaces, which is more general space. In addition, he also gave several examples of convex metric spaces which are not imbedded in any normed space or Banach space. Several papers have been devoted to the study of convex metric spaces in the literature (see Agarwal et. al [57], Beg [26, 20], Ciric [33], Guay et al [42] and Shimizu and Takahashi [65]). For the convex metric spaces, Kirk [75] and Goebel and Kirk [29] used the term "hyperbolic type space" when they studied the iterative schemes for nonexpansive mappings in the abstract framework. Some interesting results in fixed point theory has been proved in strictly convex Banach space, for example, M. Edelstein [35], F.E. Browder [11], L.P. Belluce and W.A. Kirk [31], Z. Opial [87], W.G. Dotson [74], K. Goebel and W.A. Kirk [29], P. Kuhftting [47]. Afterwards Shimizu and Takahashi [66] introduced the concept of uniform convexity in convex metric spaces and studied its properties. Recently Beg [20] introduced and studied the notion of 2-uniformly convex metric spaces. Liu [49-51] proved some sufficient and necessary conditions for Ishikawa iterative scheme and Ishikawa iterative scheme with errors to converge to fixed point for asymptotically quasinonexpansive mappings in Banach space and uniform convex Banach space. Tian [84] gave some sufficient and necessary conditions for an Ishikawa iteration sequence for an asymptotically quasi-nonexpansive mapping to converge to a fixed point in convex metric spaces. Wang and Liu [9] gave some iteration sequence with errors to approximate a fixed point of two uniformly quasi-Lipschitzian mappings in convex metric spaces. Several mathematicians have attempted transfer of structure of convexity to space which is not vector space. For example to metric space- W. Takahashi [78], J. P. Penot [28], W.A. Kirk [76], [77], to Topological space - M. R. Takovic [39] and to freely set (with help of closure operators) - A. Liepins [2]. Recently, Olatinwo [37] established the convergence of Jungck-Mann and Jungck-Ishikawa iterative processes for two non self-mappings in a convex metric space setting by employing a general 
contractive condition. In the literature of common fixed point theory many authors proved several convergence theorems for common fixed points of mean non-expansive mappings. Gu and $\mathrm{Li}$, in 2008 considered the Ishikawa iteration process to approximate the common fixed point of mean non-expansive mappings in uniformly convex Banach space. Very recently, Wang and Liu, in 2009 gave some sufficiency and necessary conditions for an Ishikawa type iteration process with errors to approximate a common fixed point of two mappings in generalized convex metric space. There are number of recent results on fixed points of asymptotically nonexpansive and asymptotically quasinonexpansive mappings in Banach spaces and metric spaces. Subsequently, Tian [84] gave some sufficient and necessary conditions for an Ishikawa iteration process of asymptotically quasi-nonexpansive mappings to converge to fixed points in convex metric spaces. Recently, Wang and Liu [9] gave some results for an Ishikawa type iteration process with errors to approximate a fixed point of two uniformly quasi-Lipschitzian mappings in generalized convex metric. The study of fixed point theory for nonexpansive mappings on hyperconvex spaces was initiated, independently, by Sine [56] and Soardi [48], and very fundamental properties about hyperconvex spaces as well as the structure of the fixed point set of nonexpansive mappings were shown by Baillon in [27]. After the fundamental work of Sine on hyperconvexity and fixed points, which may be compiled in the series of, works [36], [54], [56], [40], many authors continued stating new facts during the past decade of the twentieth century. Since then new interesting facts have been obtained about fixed points and best approximation theory in hyperconvex metric spaces.

The stability of iterative procedures plays an important role while solving the nonlinear equations obtained out of a physical problem using the advanced computational tools. Several stability results have been obtained by various authors using different contractive definitions. The first result on T-stable mappings was proved by Ostrowski for the Banach contraction principle, as mentioned by Berinde [73], but has been systematically studied by Harder in her thesis and published in the papers of Harder and Hicks( [6],[1] ). Many stability results are obtained by Harder and Hicks [1] for some iteration schemes using various contractive conditions. Olatinwo [41] gave excellent introduction and some interesting comments about several stability results established in metric spaces and normed linear spaces. Rhoades [7] generalized the results of Harder and Hicks [1] to a more general contractive mapping. In 2011, Olatinwo [38] gave the concept of T-stability in convex metric space setting.

Zamfirescu [67] established a nice generalization of the Banach's fixed point theorem by employing the following contractive condition: For a mapping $\mathrm{T}: \mathrm{E} \rightarrow \mathrm{E}$ there exist real numbers $\alpha, \beta, \gamma$ satisfying

$0 \leq \alpha<1,0 \leq \beta<\frac{1}{2}, 0 \leq \gamma<\frac{1}{2}$

Respectively such that for each $\mathrm{x}, \mathrm{y} \in \mathrm{E}$, at least one of the following is true:

$\left(\mathrm{z}_{1}\right) \quad \mathrm{d}(\mathrm{Tx}, \mathrm{T} \mathrm{y}) \leq \alpha \mathrm{d}(\mathrm{x}, \mathrm{y})$

$\left(\mathrm{z}_{2}\right) \quad \mathrm{d}(\mathrm{Tx}, \mathrm{T} \mathrm{y}) \leq \beta[\mathrm{d}(\mathrm{x}, \mathrm{T} \mathrm{x})+\mathrm{d}(\mathrm{y}, \mathrm{Ty})]$

$\left(\mathrm{z}_{3}\right) \quad \mathrm{d}(\mathrm{Tx}, \mathrm{T} \mathrm{y}) \leq \gamma[\mathrm{d}(\mathrm{x}, \mathrm{T} \mathrm{y})+\mathrm{d}(\mathrm{y}, \mathrm{Tx})]$.

The mapping $\mathrm{T}: \mathrm{E} \rightarrow \mathrm{E}$ satisfying (2) is called the Zamfirescu contraction.

Any mapping satisfying condition $\left(\mathrm{z}_{2}\right)$ of $(1.1)$ is called a Kannan mapping, while the mapping satisfying condition $\left(\mathrm{z}_{3}\right)$ is called Chatterjea operator.

In 1974, Ciric [32] introduced one of the most general contraction mappings and obtained that the unique fixed point can be approximated by Picard iteration. This mapping is called quasi-contractive, if there exists $\delta \varepsilon(0,1)$ such that $\mathrm{d}(\mathrm{Tx}, \mathrm{Ty}) \leq \delta \max \{\mathrm{d}(\mathrm{x}, \mathrm{y}), \mathrm{d}(\mathrm{x}, \mathrm{Tx}), \mathrm{d}(\mathrm{y}, \mathrm{Ty}), \mathrm{d}(\mathrm{x}, \mathrm{Ty}), \mathrm{d}(\mathrm{y}, \mathrm{Tx})\}$, for any $\mathrm{x}, \mathrm{y} \varepsilon \mathrm{E}$.

It has been shown in Berinde [70], [71], and [72] that the contractive condition (1.1) implies

$\mathrm{d}(\mathrm{T} x, \mathrm{~T} y) \leq 2 \delta \mathrm{d}(\mathrm{x}, \mathrm{T} \mathrm{x})+\delta \mathrm{d}(\mathrm{x}, \mathrm{y}), \forall \mathrm{x}, \mathrm{y} \in \mathrm{E}$,

Where $\delta=\max \left\{\alpha, \frac{\beta}{1-\beta}, \frac{\gamma}{1-\gamma}\right\}, 0 \leq \delta<1$.

Consequently, the author [70], [71], [72] used (1.2) to prove strong convergence results in Banach space setting for some iterative processes. More recently, Berinde [69] established several generalizations of Banach's fixed point theorem. In one of the results of [69], the following contractive condition was employed: For a mapping T: E $\rightarrow$ E, there exists $\alpha \in[0,1)$ and some $\mathrm{L} \geq 0$ such that for all $\mathrm{x}, \mathrm{y} \in \mathrm{E}$, we have

$\mathrm{d}(\mathrm{T} \mathrm{x}, \mathrm{T} \mathrm{y}) \leq \alpha \mathrm{M}_{1}(\mathrm{x}, \mathrm{y})+\mathrm{Lm}(\mathrm{x}, \mathrm{y})$,

Where M1 $(x, y)=\max \left\{d(x, y), d(x, T x), d(y, T y), \frac{1}{2}[d(x, T y)+d(y, T x)]\right\}$, and

$M(x, y)=\min \{d(x, T x), d(y, T y), d(x, T y), d(y, T x)\}$.

Now, in the literature of fixed point theory several iterative schemes are as follows:

Let $(X, d)$ be a complete metric space and $T: X \rightarrow X$ be a self-map of $X$. Suppose that $F_{T}=\{p \in X, T p=p\}$ is the set

of fixed points of $\mathrm{T}$. Let $\mathrm{x}_{0} \in \mathrm{X}$ as initial approximating point of the iterative schemes under consideration and take $\left\{\alpha_{n}\right\},\left\{\beta_{n}\right\},\left\{\gamma_{n}\right\}$ as the sequences in $[0,1]$.

The Picard, Mann [80], Ishikawa [63] iterative schemes are defined by the sequence $\left\{\mathrm{x}_{\mathrm{n}}\right\}$ as:

$\mathrm{x}_{\mathrm{n}+1}=\mathrm{Tx}_{\mathrm{n}}, \quad \mathrm{n}=0,1,2 \ldots$

$\mathrm{x}_{\mathrm{n}+1}=\left(1-\alpha_{\mathrm{n}}\right) \mathrm{x}_{\mathrm{n}}+\mathrm{Tx}_{\mathrm{n}}, \quad \mathrm{n}=0,1,2 \ldots$. 
$\mathrm{x}_{\mathrm{n}+1}=\left(1-\alpha_{\mathrm{n}}\right) \mathrm{x}_{\mathrm{n}}+\mathrm{Ty}_{\mathrm{n}}$,

$\mathrm{y}_{\mathrm{n}}=\left(1-\beta_{\mathrm{n}}\right) \mathrm{x}_{\mathrm{n}}+\beta_{\mathrm{n}} \mathrm{Tx}_{\mathrm{n}}, \quad \mathrm{n}=0,1,2 \ldots$

For $\mathrm{x}_{0} \in \mathrm{X}$ Noor [43] introduced the Noor three steps iteration scheme is defined as:

$\mathrm{x}_{\mathrm{n}+1}=\left(1-\alpha_{\mathrm{n}}\right) \mathrm{x}_{\mathrm{n}}+\alpha_{\mathrm{n}} \mathrm{T} \mathrm{y}_{\mathrm{n}}$,

$\mathrm{y}_{\mathrm{n}}=\left(1-\beta_{\mathrm{n}}\right) \mathrm{x}_{\mathrm{n}}+\beta_{\mathrm{n}} \mathrm{Tz}_{\mathrm{n}}$

$\mathrm{z}_{\mathrm{n}}=\left(1-\gamma_{\mathrm{n}}\right) \mathrm{x}_{\mathrm{n}}+\gamma_{\mathrm{n}} \mathrm{Tx}_{\mathrm{n}}, \quad \mathrm{n}=0,1,2 \ldots$

where $\left\{\alpha_{\mathrm{n}}\right\}_{\mathrm{n}=0}^{\infty},\left\{\beta_{\mathrm{n}}\right\}_{\mathrm{n}=0}^{\infty}$ and $\left\{\gamma_{\mathrm{n}}\right\}_{\mathrm{n}=0}^{\infty}$ are real sequences in $[0,1]$.

In 2007, Agarwal et al. [58] defined the S- iterative scheme as:

$\mathrm{x}_{\mathrm{n}+1}=\left(1-\alpha_{\mathrm{n}}\right) \mathrm{Tx}_{\mathrm{n}}+\alpha_{\mathrm{n}} \mathrm{Ty}_{\mathrm{n}}$

$\mathrm{y}_{\mathrm{n}}=\left(1-\beta_{\mathrm{n}}\right) \mathrm{x}_{\mathrm{n}}+\beta_{\mathrm{n}} \mathrm{Tx}_{\mathrm{n}}, \quad \mathrm{n}=0,1,2 \ldots$

where $\left\{\alpha_{n}\right\}_{n=0}^{\infty}$ and $\left\{\beta_{n}\right\}_{n=0}^{\infty}$ are sequences of positive numbers in $[0,1]$.

In 2011, Phuegrattana and Suantai [81] defined the SP-iterative scheme as:

$\mathrm{x}_{\mathrm{n}+1}=\left(1-\alpha_{\mathrm{n}}\right) \mathrm{x}_{\mathrm{n}}+\alpha_{\mathrm{n}} T \mathrm{y}_{\mathrm{n}}$,

$\mathrm{y}_{\mathrm{n}}=\left(1-\beta_{\mathrm{n}}\right) \mathrm{x}_{\mathrm{n}}+\beta_{\mathrm{n}} \mathrm{Tz} \mathrm{z}_{\mathrm{n}}$

$\mathrm{z}_{\mathrm{n}}=\left(1-\gamma_{\mathrm{n}}\right) \mathrm{x}_{\mathrm{n}}+\gamma_{\mathrm{n}} \mathrm{Tx}_{\mathrm{n}}, \quad \mathrm{n}=0,1,2 \ldots$

where $\left\{\alpha_{n}\right\}_{n=0}^{\infty},\left\{\beta_{n}\right\}_{n=0}^{\infty}$ and $\left\{\gamma_{n}\right\}_{n=0}^{\infty}$ are sequences in $[0,1]$.

Recently, Chugh et. al. [53] defined the new three step iterative scheme and called it as CR-iteration:

$\mathrm{x}_{\mathrm{n}+1}=\left(1-\alpha_{\mathrm{n}}\right) \mathrm{y}_{\mathrm{n}}+\alpha_{\mathrm{n}} \mathrm{Ty}_{\mathrm{n}}$,

$\mathrm{y}_{\mathrm{n}}=\left(1-\beta_{\mathrm{n}}\right) \mathrm{Tx}_{\mathrm{n}}+\beta_{\mathrm{n}} \mathrm{Tz}_{\mathrm{n}}$,

$\mathrm{z}_{\mathrm{n}}=\left(1-\gamma_{\mathrm{n}}\right) \mathrm{x}_{\mathrm{n}}+\gamma_{\mathrm{n}} \mathrm{Tx}_{\mathrm{n}}, \quad \mathrm{n}=0,1,2 \ldots$

Where $\left\{\alpha_{n}\right\}_{n=0}^{\infty}, \quad\left\{\beta_{n}\right\}_{n=0}^{\infty}$ and $\left\{\gamma_{n}\right\}_{n=0}^{\infty}$ are sequences in $[0,1]$.

\section{Remarks:}

i) If $\alpha_{\mathrm{n}}=1$ for all $\mathrm{n} \in \mathrm{N}$, then Mann iteration (1.1.2) reduces to Picard iteration (1.1.1).

ii) If $\beta_{n}=0$ for all $n \in N$, then Ishikawa iteration (1.1.3) reduces to Picard iteration (1.1.1).

iii) If $\gamma_{\mathrm{n}}=0$ for all $\mathrm{n} \in \mathrm{N}$, then Noor iteration (1.1.4) reduces to Ishikawa iteration (1.1.3).

iv) If $\beta_{\mathrm{n}}=\gamma_{\mathrm{n}}=0$ for all $\mathrm{n} \in \mathrm{N}$, then SP iteration (1.1.6) reduces to Mann iteration (1.1.2).

v) If $\alpha_{\mathrm{n}}=0$ for all $\mathrm{n} \in \mathrm{N}$, then CR iteration (1.1.7) reduces to $\mathrm{S}$ - iteration (1.1.5).

\section{Definitions}

First of all Takahashi [49] studied fixed point theory in convex metric spaces, which is more general space, and each normed linear space is a special example of the space.

Definition $2.1[20,78]$ Let $(\mathrm{X}, \mathrm{d})$ be a metric space. A mapping $\mathrm{W}: \mathrm{X} \times \mathrm{X} \times[0,1] \rightarrow \mathrm{X}$ is said to be a convex structure on $\mathrm{X}$ if for each $(\mathrm{x}, \mathrm{y}, \lambda) \in \mathrm{X} \times \mathrm{X} \times[0,1]$ and $\mathrm{u} \in \mathrm{X}$,

$\mathrm{d}(\mathrm{u}, \mathrm{W}(\mathrm{x}, \mathrm{y}, \lambda) \leq \lambda \mathrm{d}(\mathrm{u}, \mathrm{x})+(1-\lambda) \mathrm{d}(\mathrm{u}, \mathrm{y})$.

A metric space $X$ having the convex structure $W$ is called a convex metric space.

Let $(\mathrm{X}, \mathrm{d}, \mathrm{W})$ be a convex metric space. A nonempty subset $\mathrm{E}$ of $(\mathrm{X}, \mathrm{d}, \mathrm{W})$ is said to be convex if $\mathrm{W}(\mathrm{x}, \mathrm{y}, \lambda) \in \mathrm{E}$ whenever $(x, y, \lambda) \in \mathrm{E} \times \mathrm{E} \times[0,1]$.

Takahashi [78] has shown that the open ball $B(x, r)=\{x \in X: d(x, y)<r\}$ and the closed ball $\overline{B(x, r)}=\{x \in X: d(x, y) \leq r\}$ are convex.

Example 2.2: [78] Let I be the unit interval $[0,1]$ and $X$ be the family of closed intervals $\left[a_{i}, b_{i}\right]$ such that $0 \leq a_{i} \leq b_{i} \leq 1$. For $\mathrm{I}_{\mathrm{i}}=\left[\mathrm{a}_{\mathrm{i}}, \mathrm{b}_{\mathrm{i}}\right], \mathrm{I}_{\mathrm{j}}=\left[\mathrm{a}_{\mathrm{j}}, \mathrm{b}_{\mathrm{j}}\right]$, and $\lambda(0 \leq \lambda \leq 1)$, we define a mapping $\mathrm{W}$ by $\mathrm{W}\left(\mathrm{I}_{\mathrm{i}}, \mathrm{I}_{\mathrm{j}}, \lambda\right)=\left[\lambda \mathrm{a}_{\mathrm{i}}+(1-\lambda) \mathrm{a}_{\mathrm{j}}, \lambda \mathrm{b}_{\mathrm{i}}+(1-\lambda) \mathrm{b}_{\mathrm{j}}\right]$ and define a metric $\mathrm{d}$ in $\mathrm{X}$ by the Hausdorff distance, i.e.

$d\left(I_{i}, I_{j}\right)=\sup _{a \in I}\left\{\left|\inf _{b \in I_{i}}\{|a-b|\}-\inf _{c \in I_{j}}\{|a-c|\}\right|\right\}$

Definition 2.3: [24] let $X$ be a convex metric space,

(a) X Is said to be uniformly convex, if for any $\in>0$, there exists $\alpha=\alpha(\in)$ such that for all $r>0$ and $x, y, z \in X$ with $\mathrm{d}(\mathrm{z}, \mathrm{x}) \leq \mathrm{r}, \mathrm{d}(\mathrm{z}, \mathrm{y}) \leq \mathrm{r}$ and $\mathrm{d}(\mathrm{x}, \mathrm{y}) \geq \mathrm{r} \in$, give 
$\mathrm{d}\left(\mathrm{z}, \mathrm{W}\left(\mathrm{x}, \mathrm{y}, \frac{1}{2}\right)\right) \leq \mathrm{r}(1-\alpha(\in))<\mathrm{r}$.

(b) $X$ Is said to be strictly convex, if for $x, y, z \in X$ with $d(z, x) \leq r, d(z, y) \leq r$ imply that $d\left(z, W\left(x, y, \frac{1}{2}\right)\right)<r$.

It follows from the definition that a uniformly convex metric space is strictly convex but converse does not hold in general. Uniformly convex normed spaces are uniformly convex metric spaces.

Definition 2.4: [22] Let (M,d) be a metric space. A set $\mathrm{K} \subset \mathrm{M}$ is said to be convex if for each $\mathrm{x}, \mathrm{y} \in \mathrm{K}$ and for each $\mathrm{t} \in[0,1]$ there exists unique $\mathrm{z} \in \mathrm{K}$ that satisfies:

$d(x, z)=\operatorname{td}(x, y)$ and $d(z, y)=(1-t) d(x, y)$.

Definition 2.5: [9] Let $(X, d)$ be a metric space, $I=[0,1]$, and $\left\{a_{n}\right\},\left\{b_{n}\right\},\left\{c_{n}\right\}$ real sequences in $[0,1]$ with $a_{n}+b_{n}+c_{n}=1$. A mapping W: $X^{3} \times I^{3} \rightarrow X$ is said to be convex structure on $X$, if for any $\left(x, y, z, a_{n}, b_{n}, c_{n}\right) \varepsilon X^{3} \times I^{3}$ and $\mathrm{u} \varepsilon \mathrm{X}$, the following inequality holds:

$\mathrm{d}\left(\mathrm{W}\left(\mathrm{x}, \mathrm{y}, \mathrm{z}, \mathrm{a}_{\mathrm{n}}, \mathrm{b}_{\mathrm{n}}, \mathrm{c}_{\mathrm{n}}\right), \mathrm{u}\right) \leq \mathrm{a}_{\mathrm{n}} \mathrm{d}(\mathrm{x}, \mathrm{u})+\mathrm{b}_{\mathrm{n}} \mathrm{d}(\mathrm{y}, \mathrm{u})+\mathrm{c}_{\mathrm{n}} \mathrm{d}(\mathrm{z}, \mathrm{u})$

If $(X, d)$ is a metric space with a convex structure $W$, then $(X, d)$ is called a generalized convex metric space. Moreover, a nonempty subset $C$ of $X$ is said to be convex if $W\left(x, y, z, a_{n}, b_{n}, c_{n}\right) \in C$, for all $\left(x, y, z, a_{n}, b_{n}, c_{n}\right) \in C^{3} \times I^{3}$.

Remark 2.6: It is easy to see that every generalized convex metric space is a convex metric space.

Hyperconvex metric spaces were introduced by Aronszajn and Panitchpakdi to extend Hahn-Banach's theorem from the real line to more general spaces [44]. As a result they determined metric conditions guaranteeing such an extension and named spaces satisfying these conditions as hyperconvex metric spaces.

Definition 2.7: [44] A metric space $M$ is said to be hyperconvex if given any family $\left\{x_{\alpha}\right\}$ of points of $M$ and any family $\left\{r_{\alpha}\right\}$ of real numbers satisfying

$\mathrm{d}\left(\mathrm{x}_{\alpha}, \mathrm{x}_{\beta}\right) \leq \mathrm{r}_{\alpha}+\mathrm{r}_{\beta}$ then,

$$
\bigcap_{\alpha} \mathrm{B}\left(\mathrm{x}_{\alpha}, \mathrm{r}_{\alpha}\right) \neq \varnothing \text {. }
$$

A subset of a metric space with this property will be called sometimes as a hyperconvex set. Classical examples of hyperconvex spaces include the well-known spaces $1^{\infty}$ and $L^{\infty}$.

Definition 2.8: Let $\mathrm{f}, \mathrm{g}: \mathrm{X} \rightarrow \mathrm{X}$. A point $\mathrm{x} \in \mathrm{X}$ is called;

1) fixed point of $f$ if $f x=x$.

2) coincidence point of a pair ( $f, g)$ if $f x=g x$.

3) common fixed point of a pair $(f, g)$ if $x=f x=g x$.

$F(f), C(f, g)$ and $F(f, g)$ denote the set of all fixed points of $f$, coincidence points of the pair (f,g) and common fixed points of the pair $(f, g)$, respectively.

Definition 2.9: [64] let $X$ be a metric space. Let $T: D(T) \subset X \rightarrow X, F(T)$ is set of fixed points of $T$ and $D(T)$ is domain of T. T is said to be:

i) contractive if there exists a constant $\alpha \in[0,1)$ such that, $\mathrm{d}(\mathrm{Tx}, \mathrm{Ty}) \leq \alpha \mathrm{d}(\mathrm{x}, \mathrm{y}), \quad \forall \mathrm{x}, \mathrm{y} \in \mathrm{D}(\mathrm{T})$.

ii) L-Lipschitzian: if there exists a constant $\mathrm{L}>0$ such that $\mathrm{d}(\mathrm{T} x, \mathrm{Ty}) \leq \mathrm{Ld}(\mathrm{x}, \mathrm{y}), \quad \forall \mathrm{x}, \mathrm{y} \in \mathrm{D}(\mathrm{T})$.

iii) nonexpansive: if for each pair of points $x$ and $y$ in $D(T)$, we have $\mathrm{d}(\mathrm{Tx}, \mathrm{Ty}) \leq \mathrm{d}(\mathrm{x}, \mathrm{y})$.

iv) Quasi-nonexpansive mapping: if $\mathrm{F}(\mathrm{T}) \neq \phi$ and for each $\mathrm{x}$ in $\mathrm{D}(\mathrm{T})$ $\mathrm{d}(\mathrm{Tx}, \mathrm{p}) \leq \mathrm{d}(\mathrm{x}, \mathrm{p}), \quad \forall \mathrm{x} \in \mathrm{D}(\mathrm{T}), \forall \mathrm{p} \in \mathrm{F}(\mathrm{T})$.

v) Asymptotically nonexpansive mapping: if there exists a sequence $\left\{\mathrm{k}_{\mathrm{n}}\right\} \subset[1, \infty)$ with $\lim _{\mathrm{n} \rightarrow \infty} \mathrm{k}_{\mathrm{n}}=1$ such that $\mathrm{d}\left(\mathrm{T}^{\mathrm{n}} \mathrm{x}, \mathrm{T}^{\mathrm{n}} \mathrm{y}\right) \leq \mathrm{k}_{\mathrm{n}} \mathrm{d}(\mathrm{x}, \mathrm{y}), \quad \forall \mathrm{x}, \mathrm{y} \in \mathrm{D}(\mathrm{T}), \forall \mathrm{n} \in \mathrm{N}$.

vi) Asymptotically quasi-nonexpansive mapping : if $\mathrm{F}(\mathrm{T}) \neq \phi$ and there exists a sequence $\left\{\mathrm{k}_{\mathrm{n}}\right\} \subset[1, \infty)$ with $\lim _{n \rightarrow \infty} k_{n}=1$ such that $\mathrm{d}\left(\mathrm{T}^{\mathrm{n}} \mathrm{x}, \mathrm{p}\right) \leq \mathrm{k}_{\mathrm{n}} \mathrm{d}(\mathrm{x}, \mathrm{p}), \quad \forall \mathrm{x} \in \mathrm{D}(\mathrm{T}), \quad \forall \mathrm{p} \in \mathrm{F}(\mathrm{T}), \forall \mathrm{n} \in \mathrm{N}$. 
(vii)T is said to be asymptotically nonexpansive type, if

$$
\limsup _{n \rightarrow \infty}\left\{\sup _{x, y \in D(T)}\left(d\left(T^{n} x, T^{n} y\right)-d(x, y)\right)\right\} \leq 0
$$

(viii) $\mathrm{T}$ is said to be asymptotically quasi-nonexpansive type, if $\mathrm{F}(\mathrm{T}) \neq \phi$ and

$$
\limsup _{n \rightarrow \infty}\left\{\sup _{x \in D(T), p \in F(T)}\left(d\left(T^{n} x, p\right)-d(x, p)\right)\right\} \leq 0 .
$$

Definition 2.10: [12] $\mathrm{T}$ is said to be asymptotically quasi-nonexpansive mapping in intermediate sense provided that $\mathrm{T}$ is uniformly continuous and

$$
\limsup _{n \rightarrow \infty}\left\{\sup _{x \in D(T), p \in F(T)}\left(d\left(T^{n} x, p\right)-d(x, p)\right)\right\} \leq 0 .
$$

A nonexpansive mapping must be quasi-nonexpansive, and an asymptotically nonexpansive mapping must be asymptotically quasi-nonexpansive. But the converse does not hold.

Definition 2.11: [15] Let $(X, d)$ be a metric space and let $S, T: X \rightarrow X$ be two mappings. $S$ And $T$ are said to be compatible if, whenever $\left\{x_{n}\right\}$ is a sequence in $X$ such that $\operatorname{Sx}_{n}, \operatorname{Rx}_{n} \rightarrow t \in X$, then $\mathrm{d}\left(\mathrm{STx}_{\mathrm{n}}, \mathrm{TSx}_{\mathrm{n}}\right) \rightarrow 0$.

Definition 2.12: [16] A pair of mappings $S$ and $T$ is called weakly compatible pair if they commute at coincidence points.

Definition 2.13: $[8,85]$ Let $K$ be a nonempty closed subset of a complete metric space (X,d). A mapping $T: K \rightarrow K$ is said to be weakly contractive if for each $\mathrm{x}, \mathrm{y} \in \mathrm{K}$,

$\mathrm{d}(\mathrm{T}(\mathrm{x}), \mathrm{T}(\mathrm{y})) \leq \mathrm{d}(\mathrm{x}, \mathrm{y})-\psi(\mathrm{d}(\mathrm{x}, \mathrm{y}))$

Where $\psi:[0, \infty) \rightarrow[0, \infty)$ is a continuous and non-decreasing such that $\psi$ is positive on $(0, \infty), \psi(0)=0$, and $\lim _{t \rightarrow \infty} \psi(t)=\infty$.

Definition 2.14: [24] Let $K$ be a nonempty closed convex subset of a convex metric space $X$. If there exists $y_{0} \in K$ such that

$d\left(x, y_{0}\right)=d(x, K)=\inf _{y \in K} d(x, y)$,

Then $\mathrm{y}_{0}$ is called a best approximation to $\mathrm{x}$ out of $\mathrm{K} . \mathrm{P}_{\mathrm{K}}(\mathrm{x})$ denotes the set of best approximation to $\mathrm{x}$ out of $\mathrm{K}$.

Definition 2.15: [24] Let $\mathrm{K}$ be a nonempty subset of a convex metric space $\mathrm{X}$ and $\mathrm{T}: \mathrm{K} \rightarrow \mathrm{K}$ be a mapping. $\mathrm{K}$ is said to be T-regular if and only if

$\mathrm{W}\left(\mathrm{x}, \mathrm{T}(\mathrm{x}), \frac{1}{2}\right) \in \mathrm{K}$, For each $\mathrm{x} \in \mathrm{K}$.

Definition 2.16: [68] A hyperbolic space $(X, d, W)$ is a metric space $(X, d)$ together with a convexity mapping $\mathrm{W}: \mathrm{X}^{2} \times[0,1] \rightarrow \mathrm{X}$ satisfying

(W1) $\mathrm{d}(\mathrm{z}, \mathrm{W}(\mathrm{x}, \mathrm{y}, \lambda)) \leq(1-\lambda) \mathrm{d}(\mathrm{z}, \mathrm{x})+\lambda \mathrm{d}(\mathrm{z}, \mathrm{y})$

(W2) d(W(x,y, $\left.\left.\lambda_{1}\right), W\left(x, y, \lambda_{2}\right)\right)=\left|\lambda_{1}-\lambda_{2}\right| d(x, y)$

(W3) $\mathrm{W}(\mathrm{x}, \mathrm{y}, \lambda)=\mathrm{W}(\mathrm{y}, \mathrm{x}, 1-\lambda)$

(W3) $d(W(x, z, \lambda), W(y, w, \lambda)) \leq(1-\lambda) d(x, y)+\lambda d(z, w)$

For all $\mathrm{x}, \mathrm{y}, \mathrm{z}, \mathrm{w} \in \mathrm{X}$ and $\lambda, \lambda_{1}, \lambda_{2} \in[0,1]$.

Clearly every hyperbolic space is convex metric space but converse need not true. For example, if $\mathrm{X}=\mathrm{R}$ (the set of reals), $\mathrm{W}(\mathrm{x}, \mathrm{y}, \lambda)=\lambda \mathrm{x}+(1-\lambda) \mathrm{y}$ and define $\mathrm{d}(\mathrm{x}, \mathrm{y})=\frac{|\mathrm{x}-\mathrm{y}|}{1+|\mathrm{x}-\mathrm{y}|}$ for $\mathrm{x}, \mathrm{y} \in \mathrm{R}$, then $(X, \mathrm{~d}, \mathrm{~W})$ is a convex metric space but not a hyperbolic space. 
Definition 2.17: [66] A hyperbolic space $(X, d, W)$ is uniformly convex if for all $u, x, y \in X, r>0$ and $\varepsilon \in(0,2]$, there exists a $\delta \in(0,1]$ such that $d\left(\mathrm{~W}\left(\mathrm{x}, \mathrm{y}, \frac{1}{2}\right), \mathrm{u}\right) \leq(1-\delta) r$, whenever $\mathrm{d}(\mathrm{x}, \mathrm{u}) \leq \mathrm{r}, \mathrm{d}(\mathrm{y}, \mathrm{u}) \leq \mathrm{r}$ and $\mathrm{d}(\mathrm{x}, \mathrm{y}) \geq \varepsilon \mathrm{r}$. In 2011, Olatinwo [38] defined the concept of T-stability in convex metric space setting:

Definition 2.18: [32] Let $(X, d, W)$ be a convex metric space and $T: X \rightarrow X$ a self-mapping.

Let $\left\{\mathrm{x}_{\mathrm{n}}\right\}_{\mathrm{n}=0}^{\infty} \subset \mathrm{X}$ be the sequence generated by an iterative scheme involving $\mathrm{T}$ which is defined by $\mathrm{x}_{\mathrm{n}+1}=\mathrm{f}_{\mathrm{T}, \alpha_{\mathrm{n}}}^{\mathrm{x}_{\mathrm{n}}}, \mathrm{n}=0,1,2 \ldots$.

Where $\mathrm{x}_{0} \in \mathrm{X}$ is the initial approximation and $\mathrm{f}_{\mathrm{T}, \alpha_{\mathrm{n}}}^{\mathrm{x}_{\mathrm{n}}}$ is some function having convex structure such that $\alpha_{\mathrm{n}} \in[0,1]$. suppose that $\left\{\mathrm{x}_{\mathrm{n}}\right\}$ converges to a fixed point $\mathrm{p}$ of $\mathrm{T}$. Let $\left\{\mathrm{y}_{\mathrm{n}}\right\}_{\mathrm{n}=0}^{\infty} \subset \mathrm{X}$ and $\operatorname{set} \varepsilon_{\mathrm{n}}=\mathrm{d}\left(\mathrm{y}_{\mathrm{n}+1}, \mathrm{f}_{\mathrm{T}, \alpha_{\mathrm{n}}}^{\mathrm{y}_{\mathrm{n}}}\right),(\mathrm{n}=0,1,2 \ldots)$. Then, the iterative scheme (2.1.1) is said to be T-stable with respect to $T$ if and only if $\lim _{n \rightarrow \infty} \varepsilon_{n}=0$, implies $\lim _{n \rightarrow \infty} y_{n}=p$.

He also obtain some stability results for Mann and Ishikawa iteration schemes in complete convex metric space for selfmappings satisfying certain general contractive conditions.

The iteration process (5) is said to be almost T-stable or almost stable with respect to $\mathrm{T}$ if

$\sum_{n \in N} \in_{\mathrm{n}}<\infty$ Implies $\lim _{\mathrm{n} \rightarrow \infty} \mathrm{y}_{\mathrm{n}}=\mathrm{p}$.

Now the iterative schemes in terms of convex structure are as follows:

Let $(X, d, W)$ be a convex metric space and $T: X \rightarrow X$ be a selfmap of $X$. For $x_{0} \in X$,

Picard iterative scheme:

$$
\mathrm{x}_{\mathrm{n}+1}=\mathrm{Tx}_{\mathrm{n}}, \mathrm{n}=0,1,2 \ldots
$$

Mann iterative scheme:

$$
\mathrm{x}_{\mathrm{n}+1}=\mathrm{W}\left(\mathrm{x}_{\mathrm{n}}, \mathrm{Tx}_{\mathrm{n}}, \alpha_{\mathrm{n}}\right), \mathrm{n}=0,1,2 \ldots
$$

where $\left\{\alpha_{\mathrm{n}}\right\}_{\mathrm{n}=0}^{\infty}$ is a real sequence in $[0,1]$.

Ishikawa iterative scheme:

$$
\begin{aligned}
& \mathrm{x}_{\mathrm{n}+1}=\mathrm{W}\left(\mathrm{x}_{\mathrm{n}}, \mathrm{Ty}_{\mathrm{n}}, \alpha_{\mathrm{n}}\right) \\
& \mathrm{y}_{\mathrm{n}}=\mathrm{W}\left(\mathrm{x}_{\mathrm{n}}, \mathrm{Tx}_{\mathrm{n}}, \beta_{\mathrm{n}}\right), \mathrm{n}=0,1,2 \ldots .
\end{aligned}
$$

where $\left\{\alpha_{\mathrm{n}}\right\}_{\mathrm{n}=0}^{\infty}$ and $\left\{\beta_{\mathrm{n}}\right\}_{\mathrm{n}=0}^{\infty}$ are real sequences in $[0,1]$.

Noor iterative scheme:

$$
\begin{aligned}
& \mathrm{x}_{\mathrm{n}+1}=\mathrm{W}\left(\mathrm{x}_{\mathrm{n}}, \mathrm{Ty}_{\mathrm{n}}, \alpha_{\mathrm{n}}\right) \\
& \mathrm{y}_{\mathrm{n}}=\mathrm{W}\left(\mathrm{x}_{\mathrm{n}}, \mathrm{Tz}_{\mathrm{n}}, \beta_{\mathrm{n}}\right) \\
& \mathrm{z}_{\mathrm{n}}=\mathrm{W}\left(\mathrm{x}_{\mathrm{n}}, \mathrm{Tx}_{\mathrm{n}}, \gamma_{\mathrm{n}}\right), \quad \mathrm{n}=0,1,2 \ldots
\end{aligned}
$$

where $\left\{\alpha_{n}\right\}_{n=0}^{\infty},\left\{\beta_{n}\right\}_{n=0}^{\infty}$ and $\left\{\gamma_{n}\right\}_{n=0}^{\infty}$ are real sequences in $[0,1]$.

S-iterative scheme:

$$
\begin{aligned}
& x_{n+1}=W\left(T_{x}, T y_{n}, \alpha_{n}\right) \\
& y_{n}=W\left(x_{n}, T_{n}, \beta_{n}\right), \quad n=0,1,2 \ldots .
\end{aligned}
$$

where $\left\{\alpha_{n}\right\}_{n=0}^{\infty}$ and $\left\{\beta_{n}\right\}_{n=0}^{\infty}$ are sequences of positive numbers in $[0,1]$.

SP-iterative scheme:

$$
\begin{aligned}
& x_{n+1}=W\left(y_{n}, T y_{n}, \alpha_{n}\right), \\
& y_{n}=W\left(z_{n}, T z_{n}, \beta_{n}\right), \\
& z_{n}=W\left(x_{n}, T x_{n}, \gamma_{n}\right), n=0,1,2 \ldots
\end{aligned}
$$

CR-iterative scheme:

$$
\begin{aligned}
& x_{n+1}=W\left(y_{n}, T_{n}, \alpha_{n}\right), \\
& y_{n}=W\left(\operatorname{Tx}_{n}, \operatorname{Tz}_{n}, \beta_{n}\right), \\
& z_{n}=W\left(x_{n}, T_{n}, \gamma_{n}\right), n=0,1,2 \ldots
\end{aligned}
$$

where $\left\{\alpha_{\mathrm{n}}\right\}_{\mathrm{n}=0}^{\infty}, \quad\left\{\beta_{\mathrm{n}}\right\}_{\mathrm{n}=0}^{\infty}$ and $\left\{\gamma_{\mathrm{n}}\right\}_{\mathrm{n}=0}^{\infty}$ are sequences in $[0,1]$.

\section{Fixed point theorems}

Various fixed point results have been proved by many authors in convex metric spaces. This section contains some fixed point theorems obtained by the authors using different type of mappings in convex metric spaces. 
In 1970, W. Takahashi [78] introduced the concept of convexity in a metric space and studied the properties of the space called convex metric space. He formulated some fixed point theorems for nonexpansive mappings in the space. A convex metric space is said to have normal structure if for each closed bounded convex subset $\mathrm{E}$ of $\mathrm{X}$ which contains at least two points, there exists $\mathrm{x} \in \mathrm{E}$ which is not a diametric point of $\mathrm{E}$.

A convex metric space $X$ will be said to have Property (C) if every bounded decreasing net of nonempty closed convex subsets of $\mathrm{X}$ has a nonempty intersection.

Theorem 3.1: [78] Let $\mathrm{K}$ be a compact convex metric space. If $\mathrm{F}$ is a left amenable semi group of nonexpansive mappings $\mathrm{T}$ of $\mathrm{K}$ into $\mathrm{K}$, then the family $\mathrm{F}$ has invariant property in $\mathrm{K}$.

Theorem 3.2: [78] Suppose $X$ being strictly convex with property (C). Let $\mathrm{K}$ be a nonempty bounded closed convex subset of $\mathrm{X}$ with normal structure. If $\mathrm{F}$ is a commuting family of nonexpansive mappings of $\mathrm{K}$ into itself, then the family has a common fixed point in $\mathrm{K}$.

Theorem 3.3: [78] Let $\mathrm{K}$ be a compact convex metric space. If $\mathrm{F}$ is a family of nonexpansive mappings with invariant property in $\mathrm{K}$, then the family $\mathrm{F}$ has a common fixed point.

Theorem 3.4: [78] Let $\mathrm{K}$ is a compact convex subset of a Banach space and $\mathrm{X}$ be the compact convex metric space of all nonexpansive mappings of $\mathrm{K}$ into itself and $\mathrm{F}$ is a family of nonexpansive mappings of $\mathrm{X}$ into $\mathrm{X}$. If $\mathrm{F}$ has invariant property in $\mathrm{X}$, then $\mathrm{F}$ has common fixed nonexpansive mappings in $\mathrm{X}$.

O. Hadzic [45] in 1990, proved a common fixed point theorem for a family of mappings in convex metric spaces. In this paper he generalized the common fixed point theorem proved by him in [96].

Theorem 3.5: [45] Let ( $\mathrm{M}, \mathrm{d})$ be a complete convex metric space, $\mathrm{K}$ a nonempty closed subset of $\mathrm{M}, \mathrm{S}, \mathrm{T}: \mathrm{M} \rightarrow \mathrm{M}$ continuous mappings so that $\partial \mathrm{K} \subseteq \mathrm{SK} \cap \mathrm{TK}$, for every $\mathrm{i} \in \mathrm{N}, \quad \mathrm{A}_{\mathrm{i}}: \mathrm{K} \rightarrow \mathrm{M}$ continuous mappings such that $A_{i} K \cap K \subseteq S K \cap T K,\left(A_{i}, S\right)$ and $\left(A_{i}, T\right)$ compatible pairs and there exists a no decreasing function $q:[0, \infty) \rightarrow[0,1)$ such that

$\mathrm{d}\left(\mathrm{A}_{\mathrm{i}} \mathrm{x}, \mathrm{A}_{\mathrm{i}} \mathrm{y}\right) \leq \mathrm{q}(\mathrm{d}(\mathrm{Sx}, \mathrm{Ty})) \mathrm{d}(\mathrm{Sx}, \mathrm{Ty})$,

For every $i \neq j(i, j \in N)$ and every $x, y \in K$.

If for every $i \in N$ and $x \in K$ the implications

$\mathrm{Tx} \in \partial \mathrm{K} \Rightarrow \mathrm{A}_{\mathrm{i}} \mathrm{x} \in \mathrm{K} ; \mathrm{Sx} \in \partial \mathrm{K} \Rightarrow \mathrm{A}_{\mathrm{i}} \mathrm{x} \in \mathrm{K}$

Hold, then there exists $z \in K$ such that

$\mathrm{z}=\mathrm{Tz}=\mathrm{Sz}=\mathrm{A}_{\mathrm{i}} \mathrm{z}$, For every $\mathrm{i} \in \mathrm{N}$.

In 1996 Shimizu and Takahashi [66] introduced a notion of uniform convexity in convex metric spaces and proved a fixed point theorem for multivalued nonexpansive mappings in such spaces. The terms used in the proof are given as:

Let $\mathrm{X}$ be nonempty set. A nonempty family $\mathrm{F}$ of subsets of $\mathrm{X}$ is called a filter on $\mathrm{X}$ if it has the following properties: (1) $\phi \notin F$; (2) if $\mathrm{A} \subset \mathrm{B}$ and $\mathrm{A} \in \mathrm{F}$, then $\mathrm{B} \in \mathrm{F}$; (3) if $\mathrm{A}, \mathrm{B} \in \mathrm{F}$, then $\mathrm{A} \cap \mathrm{B} \in \mathrm{F}$.

A nonempty class $\mathrm{B}$ of subsets of $\mathrm{X}$ is called is called a filterbase on $\mathrm{X}$ if it has the following properties: (1) $\phi \notin \mathrm{B}$; (2) for any $A_{1}$ and $A_{2}$ in $B$, there exists $A_{3}$ in $B$ such that $A_{3} \subset A_{1} \cap A_{2}$.

Theorem 3.6: [66] Let $X$ be a complete and uniformly convex metric space. Then $X$ has the property (C).

Theorem 3.7: [66] Let $X$ be bounded, complete and uniformly convex metric space. If $T$ is a multivalued nonexpansive mapping which assigns to each point of $\mathrm{X}$ a nonempty compact subset of $\mathrm{X}$, then $\mathrm{T}$ has a fixed point in $\mathrm{X}$.

In 1999, I. Bula [22] generalized concept of strictly convex Banach space. He studied strictly convex metric space and strictly convex metric space with convex round balls.

Definition 3.8: [22] A strictly convex metric space $X$ is said to be strictly convex space with convex round balls if $\forall \mathrm{a}, \mathrm{b}, \mathrm{c} \in \mathrm{X}(\mathrm{a} \neq \mathrm{b})$ and $\forall \mathrm{t} \in[0,1]$, There exists $\mathrm{z} \in \mathrm{X}$ :

$d(a, z)=\operatorname{td}(a, b)$ And $d(z, b)=(1-t) d(a, b), d(c, z)<\max \{d(c, a), d(c, b)\}$.

Definition 3.9: [22] A family of mappings $F$ is commutative if for all $x \in K$, where $K$ is an arbitrary set, condition $f(g(x))=g(f(x))$ holds for all $f, g \in F$.

Theorem 3.10: [22] Let $\mathrm{X}$ be strictly convex metric space with convex round balls. Let $\mathrm{K} \subset \mathrm{X}$ be convex and compact set. If $\mathrm{f}: \mathrm{K} \rightarrow \mathrm{K}$ is nonexpansive mapping then $\mathrm{f}$ has a fixed point in $\mathrm{K}$. 
Theorem 3.11: [22] Let $\mathrm{X}$ be a strictly convex metric space with convex round balls. Let $\mathrm{K} \subset \mathrm{X}$ is convex and compact set. If $\mathrm{F}=\{\mathrm{f} \mid \mathrm{f}: \mathrm{K} \rightarrow \mathrm{K}\}$ is commutative family of nonexpansive mappings then there exists a common fixed point for family F, i.e.

There exists $\mathrm{x}^{*} \in \mathrm{K}$ for all $\mathrm{f} \in \mathrm{F}: \mathrm{f}\left(\mathrm{x}^{*}\right)=\mathrm{x}^{*}$

Theorem 3.12: [22] Let $X$ be a strictly convex metric space with convex round balls. Let $K \subset X$ is convex and compact set. If $\mathrm{F}=\{\mathrm{f} \mid \mathrm{f}: \mathrm{K} \rightarrow \mathrm{K}\}$ is commutative family of quasi-nonexpansive mappings then there exists a common fixed point for family $\mathrm{F}$.

Theorem 3.13: [22] Let $X$ be a strictly convex metric space with convex round balls. Let $\mathrm{K} \subset \mathrm{X}$ is convex and compact set. If $\mathrm{F}=\{\mathrm{f} \mid \mathrm{f}: \mathrm{K} \rightarrow \mathrm{K}\}$ is commutative family of asymptotically nonexpansive mappings and for all $\mathrm{f} \in \mathrm{F}:$ Fixf $\neq \varnothing$.

Then there exists a common fixed point for family $\mathrm{F}$.

In 2001, I. Beg [21] proved the existence of a fixed point for asymptotically nonexpansive mappings defined on a uniformly convex metric space.

Definition 3.14: [21] A convex metric space $X$ is said to have property (B), if for all $x, y, a \in X$, it satisfies, $\mathrm{d}(\mathrm{W}(\mathrm{x}, \mathrm{a}, \alpha), \mathrm{W}(\mathrm{y}, \mathrm{a}, \alpha))=\alpha \mathrm{d}(\mathrm{x}, \mathrm{y})$.

Taking $\mathrm{x}=\mathrm{a}$, property (B) implies $\alpha \mathrm{d}(\mathrm{a}, \mathrm{y})=\mathrm{d}(\mathrm{a}, \mathrm{W}(\mathrm{y}, \mathrm{a}, \alpha))$.

Definition 3.15: [21] A uniformly convex metric space $X$ is said to be 2-uniformly convex if there exists a constant $\mathrm{c}>0$ such that $\delta(\varepsilon)>\mathrm{c} \varepsilon^{2}$.

Definition 3.16: [21] Let $(\mathrm{X}, \mathrm{d})$ be a metric space and $\mathrm{Y}$ a topological space. A mapping $\mathrm{T}: \mathrm{X} \rightarrow \mathrm{Y}$ is said to be completely continuous if the image of each bounded set in $\mathrm{X}$ is contained in a compact subset of $\mathrm{Y}$.

Definition 3.17: [21] Let A be a nonempty subset of a metric space (X,d) and $L>0$. A mapping $\mathrm{T}: \mathrm{A} \rightarrow \mathrm{A}$ is said to be uniformly L- Lipschitzian if $d\left(T^{n} x, T^{n} y\right) \leq \operatorname{Ld}(x, y)$ for each $x, y$ in $A$ and for all $n \in N$.

Theorem 3.18: [21] Let A be a nonempty closed bounded convex subset of a uniformly convex metric space (X, d) and let $\mathrm{T}: \mathrm{A} \rightarrow \mathrm{A}$ bean asymptotically nonexpansive mapping. Then $\mathrm{T}$ has a fixed point.

Theorem 3.19: [21] Let A be a nonempty closed bounded convex subset of a uniformly convex complete metric space $(\mathrm{X}, \mathrm{d})$ and let $\mathrm{T}: \mathrm{A} \rightarrow \mathrm{A}$ bean asymptotically nonexpansive mapping. Then the set Fix $(\mathrm{T})$ of fixed points of $\mathrm{T}$ is closed and convex.

Theorem 3.20: [21] Let $(X, d)$ be a convex metric space and A a nonempty convex subset of $X$. Let $L>0$; $T: A \rightarrow A$ uniformly L- Lipschitzian; $\mathrm{x}_{1} \in A$. Define $\mathrm{z}_{\mathrm{n}}=\mathrm{W}\left(\mathrm{T}^{\mathrm{n}} \mathrm{x}_{\mathrm{n}}, \mathrm{x}_{\mathrm{n}}, \frac{1}{2}\right)$, and $\mathrm{x}_{\mathrm{n}+1}=\mathrm{W}\left(\mathrm{T}^{\mathrm{n}} \mathrm{x}_{\mathrm{n}}, \mathrm{x}_{\mathrm{n}}, \frac{1}{2}\right)$

and set $c_{n}=d\left(T^{n} x_{n}, x_{n}\right)$ for all $n \in N$. Then

$d\left(x_{n}, T x_{n}\right) c_{n}+c_{n-1}\left(L+3 L^{2}+2 L^{3}\right)$

for all $\mathrm{n} \in \mathrm{N}$.

Theorem 3.21: [21] Let (X, d) be a 2-uniformly convex metric space having property (B); A a nonempty closed bounded convex subset of $\mathrm{X} ; \mathrm{T}: \mathrm{A} \rightarrow \mathrm{A}$ asymptotically nonexpansive with sequence $\left\{\mathrm{k}_{\mathrm{n}}\right\} \in[1,+\infty)^{\mathrm{N}}$; $\sum_{n=1}^{\infty}\left(k_{n}^{2}-1\right)<+\infty$

Let $x_{1} \in A ; \quad x_{n+1}=\left(T^{n} x_{n}, x_{n}, \frac{1}{2}\right)$ for all $n \in N$. Then $\lim _{n \rightarrow \infty} d\left(x_{n}, T x_{n}\right)=0$.

Theorem 3.22: [21] Let (X, d) be a 2-uniformly convex metric space having property (B); A a nonempty closed bounded convex subset of $\mathrm{X} ; \mathrm{T}: \mathrm{A} \rightarrow \mathrm{A}$ completely continuous asymptotically nonexpansive mapping with sequence

$\left\{\mathrm{k}_{\mathrm{n}}\right\} \in[1,+\infty)^{\mathrm{N} ;} \sum_{\mathrm{n}=1}^{\infty}\left(\mathrm{k}_{\mathrm{n}}^{2}-1\right)<\infty$ 
Let $\mathrm{x}_{1} \in A ; \mathrm{x}_{\mathrm{n}+1}=\left(\mathrm{T}^{\mathrm{n}} \mathrm{x}_{\mathrm{n}}, \mathrm{x}_{\mathrm{n}}, \frac{1}{2}\right)$ for all $\mathrm{n} \in \mathrm{N}$. Then $\left\{\mathrm{x}_{\mathrm{n}}\right\}$ converges to some fixed point of $\mathrm{T}$.

In 2002, S. Sharma and B. Deshpande [60] proved common fixed point theorems of Gregus type for three mappings in convex metric spaces.

Definition 3.23: [60] Let $(X, d)$ be a convex metric space and $K$ be a convex subset of $X$. A mapping $S: K \rightarrow K$ is said to be W-affine if

$\mathrm{SW}(\mathrm{x}, \mathrm{y}, \lambda)=\mathrm{W}(\mathrm{Sx}, \mathrm{Sy}, \lambda)$ for all $(\mathrm{x}, \mathrm{y}, \lambda) \in \mathrm{K} \times \mathrm{K} \times \mathrm{J}$.

Theorem 3.24: [60] Let $X$ be a complete metric space with a convex structure $W$ and $K$ is a nonempty closed convex subset of $\mathrm{X}$. Let $\mathrm{A}, \mathrm{B}$ and $\mathrm{S}$ be three mappings of $\mathrm{K}$ into it satisfying the following conditions:

(1.1) $\mathrm{S}$ and $\mathrm{B}$ are $\mathrm{W}-$ affine,

(1.2) $\mathrm{S}$ is continuous,

(1.3) the pair $(\mathrm{S}, \mathrm{A})$ and $(\mathrm{S}, \mathrm{B})$ are compatible,

(1.4) $\mathrm{A}(\mathrm{K}) \subset \mathrm{S}(\mathrm{K}), \mathrm{B}(\mathrm{K}) \subset \mathrm{S}(\mathrm{K})$,

(1.5) $d^{\mathrm{p}}(\mathrm{Ax}, \mathrm{By}) \leq \operatorname{ad}^{\mathrm{p}}(\mathrm{Sx}, \mathrm{Sy})+\mathrm{b} \max \left\{\mathrm{d}^{\mathrm{p}}(\mathrm{Ax}, \mathrm{Sx}), \mathrm{d}^{\mathrm{p}}(\mathrm{By}, \mathrm{Sy})\right\}$

$+c \max \left\{d^{p}(S x, S y), d^{p}(A x, S x), d^{p}(B y, S y)\right\}$ For all $x, y$ in $K$, where $a, b, c>0, p \geq 1$,

$a+b+c=1$ And $\max \left\{\frac{\left(1-b^{2}\right)}{a}, b+c\right\}<\left(3-3^{1-p}\right)\left(3^{p}-1\right)^{-1}$.

Then $\mathrm{A}, \mathrm{B}$ and $\mathrm{S}$ have a unique common fixed point $\mathrm{z}^{*}$ in $\mathrm{K}$. Also $\mathrm{A}$ and $\mathrm{B}$ are continuous at $\mathrm{z}^{*}$.

In 2005, S. Sharma and B. Deshpande [61] proved common fixed point theorems of Gregus type for three discontinuous and weak compatible mappings in convex metric spaces. Result given by them is:

Theorem 3.25: [61] Let $\mathrm{X}$ is a complete convex metric space with a convex structure $\mathrm{W}$ and $\mathrm{K}$ is a nonempty closed convex subset of $\mathrm{X}$. Let $\mathrm{A}, \mathrm{B}$ and $\mathrm{S}$ be three mappings of $\mathrm{K}$ into itself satisfying the following conditions:

(A1) $\mathrm{S}$ and $\mathrm{B}$ are $\mathrm{W}$-affine,

(A2) the pairs $(\mathrm{S}, \mathrm{A})$ and $(\mathrm{S}, \mathrm{B})$ are weakly compatible,

(A3) $\mathrm{A}(\mathrm{K}) \subset \mathrm{S}(\mathrm{K}), \quad \mathrm{B}(\mathrm{K}) \subset \mathrm{S}(\mathrm{K})$,

(A4) $d^{\mathrm{p}}(\mathrm{Ax}, \mathrm{By}) \leq \mathrm{ad}^{\mathrm{p}}(\mathrm{Sx}, \mathrm{Sy})+\mathrm{b} \max \left\{\mathrm{d}^{\mathrm{p}}(\mathrm{Ax}, \mathrm{Sx}), \mathrm{d}^{\mathrm{p}}(\mathrm{By}, \mathrm{Sy})\right\}$

$+\mathrm{c} \max \left\{\mathrm{d}^{\mathrm{p}}(\mathrm{Sx}, \mathrm{Sy}), \mathrm{d}^{\mathrm{p}}(\mathrm{Ax}, \mathrm{Sx}), \mathrm{d}^{\mathrm{p}}(\mathrm{By}, \mathrm{Sy})\right\}$

For all $\mathrm{x}, \mathrm{y}$ in $\mathrm{K}$, where $\mathrm{a}, \mathrm{b}, \mathrm{c}>0, \mathrm{p} \geq 1, \mathrm{a}+\mathrm{b}+\mathrm{c}=1,(1-\mathrm{b}) / 2 \mathrm{a}<\left(3^{\mathrm{p}}+1\right)^{-1}$ and $\mathrm{b}+\mathrm{c}<\left(3-3^{1-\mathrm{p}}\right)\left(3^{\mathrm{p}}-1\right)^{-1}$.

Then $\mathrm{A}, \mathrm{B}$ and $\mathrm{S}$ have a unique common fixed point in $\mathrm{K}$.

In 2007, I. Beg and M. Abbas [25] studied the common fixed point for R-subweakly and uniformly R-subweakly commuting mappings in the setting of a convex metric space. They also established results on invariant approximation for these mapping.

Let $\mathrm{X}$ be a convex metric space. A nonempty subset $\mathrm{F}$ of $\mathrm{X}$ is said to be q-starshaped if there exists $\mathrm{q}$ in $\mathrm{F}$ such that $\mathrm{W}(\mathrm{q}, \mathrm{x}, \lambda) \in \mathrm{F}$ whenever $(\mathrm{x}, \lambda) \in \mathrm{F} \times[0,1]$.

Let $\mathrm{F}$ be a q-starshaped subset of $\mathrm{X}$ and $\mathrm{T}, \mathrm{S}: \mathrm{F} \rightarrow \mathrm{F}$. Put, $\mathrm{Y}_{\mathrm{q}}^{\mathrm{T}(\mathrm{x})}=\left\{\mathrm{y}_{\lambda}: \mathrm{y}_{\lambda}=\mathrm{W}(\mathrm{q}, \mathrm{T}(\mathrm{x}), \lambda)\right.$ and $\left.\lambda \in[0,1]\right\}$.

Now, for each $x$ in $X, d\left(S(x), Y_{q}^{T(x)}\right)=\inf _{\lambda \in[0,1]} d\left(S(x), y_{\lambda}\right)$. Moreover if for $u \in X, x \in F, Y_{u}^{x} \cap F$ is disjoint then $x \in \partial F$ (boundary of $\mathrm{F}$ ).

Definition 3.26: [25] A self-mapping $T$ on a convex metric space $X$ is said to satisfy a property (I) if, $\mathrm{T}(\mathrm{W}(\mathrm{x}, \mathrm{y}, \lambda))=\mathrm{W}(\mathrm{Tx}, \mathrm{Ty}, \lambda)$.

The set of fixed points of $\mathrm{T}$ is denoted by Fix $(\mathrm{T})$.

Definition 3.27: [25] Let $(X, d)$ be a convex metric space and $F$ be a q-star shaped subset of $X, S$ and $T$ be selfmappings on $X$ and $q \in \operatorname{Fix}(S)$, then $T$ is said to be:

1) An S-contraction if there exists $k \in(0,1)$ such that $\mathrm{d}(\mathrm{Tx}, \mathrm{Ty}) \leq \mathrm{kd}(\mathrm{Sx}, \mathrm{Sy})$. 
2) An asymptotically $\mathrm{S}$-nonexpansive if there exists a sequence $\left\{\mathrm{k}_{\mathrm{n}}\right\}, \mathrm{k}_{\mathrm{n}} \geq 1$, with $\lim _{\mathrm{n} \rightarrow \infty} \mathrm{k}_{\mathrm{n}}=1$ such that $\mathrm{d}\left(\mathrm{T}^{\mathrm{n}}(\mathrm{x}), \mathrm{T}^{\mathrm{n}}(\mathrm{y})\right) \leq \mathrm{k}_{\mathrm{n}} \mathrm{d}\left(\mathrm{Sx}\right.$, Sy) for each $\mathrm{x}, \mathrm{y}$ in $\mathrm{F}$ and each $\mathrm{n} \in \mathrm{N}$. If $\mathrm{k}_{\mathrm{n}}=1$, for all $\mathrm{n} \in \mathrm{N}$, then $\mathrm{T}$ is known as a S-nonexpansive mapping. If $\mathrm{S}=\mathrm{I}$ (Identity map), then $\mathrm{T}$ is asymptotically nonexpansive mapping.

3) R-weakly commuting if there exists a real number $\mathrm{R}>0$ such that $\mathrm{d}(\mathrm{TSx}, \mathrm{STx}) \leq \mathrm{Rd}(\mathrm{Tx}, \mathrm{Sx})$; For all $\mathrm{x}$ in F.

4) R-sub weakly commuting if there exists a real number $\mathrm{R}>0$ such that $\mathrm{d}(\mathrm{TSx}, \mathrm{STx}) \leq \operatorname{Rd}\left(\mathrm{Sx}, \mathrm{Y}_{\mathrm{q}}^{\mathrm{T}(\mathrm{x})}\right)$; For all $\mathrm{x}$ in $\mathrm{F}$.

5) Uniformly R-sub weakly commuting if there exists a real number $\mathrm{R}>0$ such that $\mathrm{d}\left(\mathrm{T}^{\mathrm{n}} \mathrm{Sx}, \mathrm{ST}^{\mathrm{n}} \mathrm{x}\right) \leq \mathrm{Rd}\left(\mathrm{Sx}, \mathrm{Y}_{\mathrm{q}}^{\mathrm{T}(\mathrm{x})}\right)$; For all $\mathrm{x}$ in $\mathrm{F}$.

Theorem 3.28: [25] Let $F$ be a nonempty closed $q$-star shaped subset of a convex metric space $(\mathrm{X}, \mathrm{d})$ and let $\mathrm{T}$ and $\mathrm{S}$ be two R-sub weakly commuting mappings on $\mathrm{F}$ such that $\mathrm{T}(\mathrm{F}) \subset \mathrm{S}(\mathrm{F})$, $\operatorname{cl}(\mathrm{T}(\mathrm{F})$ ) is compact and $\mathrm{q} \in \mathrm{Fix}(\mathrm{S})$. If $\mathrm{T}$ is continuous $\mathrm{S}$ - nonexpansive and $\mathrm{S}$ satisfy property (I) then $\operatorname{Fix}(\mathrm{T}) \cap \mathrm{Fix}(\mathrm{S})$ is nonempty.

Theorem 3.29: [25] Let $F$ be a nonempty closed subset of a convex complete metric space (X, $d)$ and let $T$ and $S$ be two mappings on $\mathrm{F}$ such that $\mathrm{T}(\mathrm{F}-\{\mathrm{u}\}) \subset \mathrm{S}(\mathrm{F}-\{\mathrm{u}\})$, where $\mathrm{u} \in \mathrm{Fix}(\mathrm{S})$. Suppose that $\mathrm{T}$ is an $\mathrm{S}-$ contraction and continuous. If $\mathrm{S}$ and $\mathrm{T}$ are $\mathrm{R}$-weakly commuting mappings on $\mathrm{F}-\{\mathrm{u}\}$, then $\operatorname{Fix}(\mathrm{T}) \cap \mathrm{Fix}(\mathrm{S})$ is singleton in $\mathrm{F}$.

Theorem 3.30: [25] Let $F$ be a nonempty closed $q$-star shaped subset of a convex metric space $(\mathrm{X}, \mathrm{d})$ and let $\mathrm{T}$ and $\mathrm{S}$ be two uniformly R-sub weakly commuting mappings on $\mathrm{F}-\{\mathrm{q}\}$ such that $\mathrm{S}(\mathrm{F})=\mathrm{F}$ and $\mathrm{T}(\mathrm{F}-\{\mathrm{q}\}) \subset \mathrm{S}(\mathrm{F}-\{\mathrm{q}\})$, where $\mathrm{q} \in \mathrm{Fix}(\mathrm{S})$. Suppose that $\mathrm{T}$ is continuous asymptotically $\mathrm{S}-$ nonexpansive with sequence $\left\{\mathrm{k}_{\mathrm{n}}\right\}$ and $\mathrm{S}$ satisfy property I. For each $\mathrm{n} \geq 1$, define a mapping $\mathrm{T}_{\mathrm{n}}$ on $\mathrm{F}$ by $\mathrm{T}_{\mathrm{n}} \mathrm{x}=\mathrm{W}\left(\mathrm{T}^{\mathrm{n}}(\mathrm{x}), \mathrm{q}, \alpha_{\mathrm{n}}\right)$, where $\alpha_{n}=\frac{\lambda_{n}}{k_{n}}$ and $\left\{\lambda_{n}\right\}$ is a sequence in $(0,1)$ with $\lim _{n \rightarrow \infty} \lambda_{n}=1$. Then for each $n \in N, \operatorname{Fix}\left(T_{n}\right) \cap \operatorname{Fix}(S)$ is singleton.

Theorem 3.31: [25] Let $F$ be a nonempty closed $q$-starshaped subset of a convex metric space $(X, d)$ and let $T$ and $S$ be two continuous self-mappings on $F$ such that $S(F)=F$ and $T(F-\{q\}) \subset S(F-\{q\})$, $\mathrm{q} \in \operatorname{Fix}(\mathrm{S})$. Suppose $\mathrm{T}$ is uniformly asymptotically regular, asymptotically $\mathrm{S}$ - nonexpansive and $\mathrm{S}$ satisfies property (I). If $\mathrm{cl}(\mathrm{F}-\{\mathrm{q}\})$ is compact and $\mathrm{S}$ and $\mathrm{T}$ are uniformly $\mathrm{R}-$ sub weakly commuting mappings on $\mathrm{F}-\{\mathrm{q}\}$. Then $\operatorname{Fix}(\mathrm{T}) \cap \operatorname{Fix}(\mathrm{S})$ is singleton in $\mathrm{F}$.

Theorem 3.32: [25] Let $F$ be a nonempty $q$-star shaped complete subset of a convex metric space and and $T$, $f$ and $\mathrm{g}$ be self-mappings on $\mathrm{X}$. Suppose $\mathrm{T}$ is continuous and $\mathrm{cl}(\mathrm{T}(\mathrm{F})$ ) is compact and $\mathrm{f}$ and $\mathrm{g}$ satisfy property (I) and continuous and $\mathrm{T}(\mathrm{F}) \subset \mathrm{f}(\mathrm{F}) \cap \mathrm{g}(\mathrm{F})$. If the pairs $\{\mathrm{T}, \mathrm{f}\}$ and $\{\mathrm{T}, \mathrm{g}\}$ are $\mathrm{R}-\mathrm{sub}$ weakly commuting and satisfy for all $\mathrm{x}, \mathrm{y} \in \mathrm{F}$,

$\mathrm{d}(\mathrm{Tx}, \mathrm{Ty}) \leq \max \left\{\mathrm{d}(\mathrm{fx}, \mathrm{gy}), \mathrm{d}\left(\mathrm{fx}, \mathrm{Y}_{\mathrm{q}}^{\mathrm{T}(\mathrm{x})}\right), \mathrm{d}\left(\mathrm{gy}, \mathrm{Y}_{\mathrm{q}}^{\mathrm{T}(\mathrm{y})}\right), \frac{1}{2}\left[\mathrm{~d}\left(\mathrm{fx}, \mathrm{Y}_{\mathrm{q}}^{\mathrm{T}(\mathrm{y})}\right)+\mathrm{d}\left(\mathrm{gy}, \mathrm{Y}_{\mathrm{q}}^{\mathrm{T}(\mathrm{x})}\right)\right]\right\}$,

Then $\mathrm{T}, \mathrm{f}$ and $\mathrm{g}$ have common fixed point.

Theorem 3.33: [25] Let $M$ be a nonempty subset of a convex metric space (X,d) and let $T$ and $S$ be two continuous self-mappings on $X$ such that and $T(\partial M \cap M) \subset M, u \in F i x(S) \cap F i x(T)$ for some $u$ in $X$. Suppose $T$ is uniformly asymptotically regular, asymptotically $S$ - nonexpansive and $S$ satisfies property (I) on $P_{M}(u)$ with $S\left(P_{M}(u)\right)=P_{M}(u)$, $\mathrm{q} \in \operatorname{Fix}(\mathrm{S})$ and $\mathrm{P}_{\mathrm{M}}(\mathrm{u})$ is $\mathrm{q}$-star shaped. If $\operatorname{cl}\left(\mathrm{P}_{\mathrm{M}}(\mathrm{u})\right)$ is compact and $\mathrm{P}_{\mathrm{M}}(\mathrm{u})$ is complete and $\mathrm{S}$ and $\mathrm{T}$ are uniformly sub-weakly commuting mappings on $\quad \mathrm{P}_{\mathrm{M}}(\mathrm{u}) \cup\{\mathrm{u}\} \quad$ satisfying $\mathrm{d}(\mathrm{Tx}, \mathrm{Ty}) \leq \mathrm{d}(\mathrm{Sx}, \mathrm{Su})$. Then $\mathrm{P}_{\mathrm{M}}(\mathrm{u}) \cap \operatorname{Fix}(\mathrm{T}) \cap \operatorname{Fix}(\mathrm{S}) \neq \phi$.

Theorem 3.34: [25] Let $M$ be a nonempty subset of a convex metric space (X,d) and $T, f$ and $g$ be self-maps on $X$ such that $\mathrm{u}$ is common fixed point of $\mathrm{f}, \mathrm{g}$ and $\mathrm{T}$ and $\mathrm{T}(\partial \mathrm{M} \cap \mathrm{M}) \subset \mathrm{M}$. Suppose $\mathrm{f}$ and $\mathrm{g}$ are continuous on $\mathrm{P}_{\mathrm{M}}(\mathrm{u})$ 
and satisfy property $\mathrm{I}$ with $\mathrm{P}_{\mathrm{M}}(\mathrm{u})$ is a $\mathrm{q}$-starshaped with $\mathrm{f}\left(\mathrm{P}_{\mathrm{M}}(\mathrm{u})\right)=\mathrm{P}_{\mathrm{M}}(\mathrm{u})=\mathrm{g}\left(\mathrm{P}_{\mathrm{M}}(\mathrm{u})\right)$ and $\mathrm{q} \in \operatorname{Fix}(\mathrm{f}) \cap$ Fix $(\mathrm{g})$. If the pairs $\{\mathrm{T}, \mathrm{f}\}$ and $\{\mathrm{T}, \mathrm{g}\}$ are $\mathrm{R}$ - subweakly commuting and satisfy for all $\mathrm{x} \in \mathrm{P}_{\mathrm{M}}(\mathrm{u}) \cup\{\mathrm{u}\}$

$$
d(T x, T y) \leq \begin{cases}d(f x, g u), & \text { if } y=u ; \\ \max \left\{d(f x, g y), d\left(f x, Y_{q}^{T(x)}\right), d\left(g y, Y_{q}^{T(y)}\right),\right. & \\ \left.\frac{1}{2}\left[d\left(f x, Y_{q}^{T(y)}\right)+d\left(g y, Y_{q}^{T(x)}\right)\right]\right\}, & \text { if } y \in P_{M}(u) .\end{cases}
$$

If $\mathrm{cl}\left(\mathrm{P}_{\mathrm{M}}(\mathrm{u})\right)$ is compact and $\mathrm{P}_{\mathrm{M}}(\mathrm{u})$ is complete then $\mathrm{P}_{\mathrm{M}}(\mathrm{u}) \cap \operatorname{Fix}(\mathrm{T}) \cap \operatorname{Fix}(\mathrm{f}) \cap \operatorname{Fix}(\mathrm{g})$ is nonempty.

\section{Convergence results}

In convex metric spaces, many authors established several results on the convergence of different iterative schemes defined in the literature. Here, in this section we give some of the results in which the convergence of some iterative schemes using different contractive conditions to a fixed point are shown in the setting of convex metric spaces.

In 2002, K. P. R. Sastry, G. V. R. Babu and Ch. Srinivasa Rao [30] showed the convergence of Ishikawa iterative scheme for a nonlinear quasi-contractive pair of self-maps of a nonempty closed convex subset of a complete convex metric space to a unique common fixed point.

Definition 4.1: [32] Let (X,d) be a metric space. A selfmap $\mathrm{T}: \mathrm{X} \rightarrow \mathrm{X}$ is said to be quasi-contractive if there exists a number $\mathrm{k}, 0 \leq \mathrm{k}<1$ such that for each $\mathrm{x}, \mathrm{y}$ in $\mathrm{X}$

$\mathrm{d}(\mathrm{Tx}, \mathrm{Ty}) \leq \mathrm{kM}(\mathrm{x}, \mathrm{y})$,

$M(x, y)=\max \{d(x, y), d(x, T x), d(x, T y), d(y, T x), d(y, T y)\}$.

Theorem 4.2: [30] Let $(X, d)$ be a complete convex metric space, with a convex structure W. Let $\mathrm{S}$ and $\mathrm{T}$ be self-maps of $\mathrm{X}$ satisfying the inequality

$\max \{\mathrm{d}(\mathrm{Sx}, \mathrm{Sy}), \mathrm{d}(\mathrm{Tx}, \mathrm{Ty}), \mathrm{d}(\mathrm{Sx}, \mathrm{Ty})\} \leq \omega(\mathrm{M}(\mathrm{x}, \mathrm{y})) \quad \forall \mathrm{x}, \mathrm{y} \in \mathrm{X}$

Where $M(x, y)=\max \{d(x, y), d(x, S x), d(x, S y), d(y, S x), d(x, T x), d(y, T y), d(y, S y)$,

$\mathrm{d}(\mathrm{x}, \mathrm{Ty}), \mathrm{d}(\mathrm{y}, \mathrm{Tx}), \mathrm{d}(\mathrm{Sx}, \mathrm{Tx}), \mathrm{d}(\mathrm{Sy}, \mathrm{Ty})\}$.

Where $\omega:(0,+\infty) \rightarrow(0,+\infty)$ satisfying,

$0<\omega\left(\mathrm{t}_{+}\right)<\mathrm{t}$ For each $\mathrm{t}>0$,

$\omega(\mathrm{t})$ Is nondecreasing and $\lim _{\mathrm{t} \rightarrow \infty}(\mathrm{t}-\omega(\mathrm{t}))=+\infty$.

For $\mathrm{x}_{0} \in \mathrm{X}$, define the Ishikawa iteration scheme by

$\mathrm{y}_{\mathrm{n}}=\mathrm{W}\left(\mathrm{Tx}_{\mathrm{n}}, \mathrm{x}_{\mathrm{n}}, \beta_{\mathrm{n}}\right)$ Where $0<\alpha_{\mathrm{n}}, \beta_{\mathrm{n}}<1$ for all $\mathrm{n}$ and

$\mathrm{x}_{\mathrm{n}+1}=\mathrm{W}\left(\mathrm{Sy}_{\mathrm{n}}, \mathrm{x}_{\mathrm{n}}, \alpha_{\mathrm{n}}\right)$ With $\sum \alpha_{\mathrm{n}}=\infty$.

Then the sequence $\left\{x_{n}\right\}$ converges, say to " $z$ " and this is the unique common fixed point of $S$ and $T$.

In 2006, A. Rafiq and S. Zafar [3] generalized the results of Naimpally and Singh [86], and Ciric et al [85] to a pair of mappings $\mathrm{S}$ and $\mathrm{T}$, defined on a generalized convex metric space.

Ciric et al [34] generalized the results of Naimpally and Singh [62] to a pair of mappings S and T, defined on a convex metric space. They proved that if the sequence of Ishikawa iterations associated with $\mathrm{S}$ and $\mathrm{T}$ converges, then its limit point is the common fixed points of $\mathrm{S}$ and $\mathrm{T}$, which satisfy the following conditions:

$($ CUK $) d($ Sx, Ty $) \leq h[d(x, y)+d(x, T y)+d(y, S x)]$,

Where $0<\mathrm{h}<1$. The condition (CUK) is very general, since by the triangle inequality, condition (CUK) is always satisfied with $\mathrm{h}=1$.

The results established by A. Rafiq and S. Zafar are as follows:

Theorem 4.3: [3] Let $\mathrm{C} b$ e a nonempty closed convex subset of a generalized convex metric space $\mathrm{X}$ and let $\mathrm{S}$, $\mathrm{T}: \mathrm{X}$ $\rightarrow X$ be self-mappings satisfying (CUK) for all $x, y$ in C. Suppose that $\left\{x_{n}\right\}$ is defined by,

$\mathrm{x}_{0} \in \mathrm{C}, \mathrm{x}_{\mathrm{n}}=\mathrm{W}\left(\mathrm{x}_{\mathrm{n}-1}, \mathrm{Sy}_{\mathrm{n}}, \mathrm{u}_{\mathrm{n}} ; \mathrm{a}_{\mathrm{n}}, \mathrm{b}_{\mathrm{n}}, \mathrm{c}_{\mathrm{n}}\right)$

$\mathrm{y}_{\mathrm{n}}=\mathrm{W}\left(\mathrm{x}_{\mathrm{n}-1}, \mathrm{Tx}_{\mathrm{n}}, \mathrm{v}_{\mathrm{n}} ; \mathrm{a}_{\mathrm{n}}^{\prime}, \mathrm{b}_{\mathrm{n}}^{\prime}, \mathrm{c}_{\mathrm{n}}^{\prime}\right), \mathrm{n} \geq 1$, 
where $\left\{a_{n}\right\},\left\{b_{n}\right\},\left\{c_{n}\right\},\left\{a_{n}^{\prime}\right\},\left\{b_{n}^{\prime}\right\},\left\{c_{n}^{\prime}\right\}$ are sequences in $[0,1]$ such that $a_{n}+b_{n}+c_{n}=1=a_{n}^{\prime}+b_{n}^{\prime}+c_{n}^{\prime}$ and $\left\{u_{n}\right\},\left\{v_{n}\right\}$ are bounded sequences in $\mathrm{C}$, is called Xu-Ishikawa type iteration process, satisfying $\left\{b_{n}\right\} \subset[\delta, 1-\delta]$ for some $\delta \in(0,1)$ and $\lim _{n \rightarrow \infty} c_{n}=0=\lim _{n \rightarrow \infty} c_{n}^{\prime}$. If $\left\{x_{n}\right\}$ converges to some point $p \in C$, then $p$ is the common fixed point of $S$ and $T$.

Theorem 4.4: [3] Let $C$ be a nonempty closed convex subset of a generalized convex metric space $X$ and let $S$, T: $X$ $\rightarrow \mathrm{X}$ be self-mappings satisfying (CUK) for all $\mathrm{x}, \mathrm{y}$ in C. Suppose that $\left\{\mathrm{x}_{\mathrm{n}}\right\}$ is defined by

$\mathrm{x}_{0} \in \mathrm{C}, \mathrm{x}_{\mathrm{n}}=\mathrm{W}\left(\mathrm{x}_{\mathrm{n}-1}, \mathrm{STx}_{\mathrm{n}}, \mathrm{u}_{\mathrm{n}} ; \mathrm{a}_{\mathrm{n}}, \mathrm{b}_{\mathrm{n}}, \mathrm{c}_{\mathrm{n}}\right), \mathrm{n} \geq 1$,

where $\left\{a_{n}\right\},\left\{b_{n}\right\},\left\{c_{n}\right\}$ are sequences in $[0,1]$ such that $a_{n}+b_{n}+c_{n}=1$ and $\left\{u_{n}\right\}$ is bounded sequence in $C$, is called Xu-Mann type iteration process, satisfying $\left\{b_{n}\right\} \subset[\delta, 1-\delta]$ for some $\delta \in(0,1)$ and $\lim _{n \rightarrow \infty} c_{n}=0$. If $\left\{x_{n}\right\}$ converges to some point $\mathrm{p} \in \mathrm{C}$, then $\mathrm{p}$ is the common fixed point of $\mathrm{S}$ and $\mathrm{T}$.

Theorem 4.5: [3] Let $X$ be a normed linear space and $C$ be a closed convex subset of $X$ and let $S$, T: $X \rightarrow X$ be selfmappings satisfying (CUK) for all $x, y$ in $C$. Suppose that $\left\{x_{n}\right\}$ is defined by $x_{0} \in C, x_{n}=a_{n} x_{n-1}+b_{n} S y_{n}+c_{n} u_{n}, y_{n}=a_{n}^{\prime} x_{n-1}+b_{n}^{\prime} T x_{n}+c_{n}^{\prime} v_{n}, n \geq 1$,

where $\left\{a_{n}\right\},\left\{b_{n}\right\},\left\{c_{n}\right\},\left\{a_{n}^{\prime}\right\},\left\{b_{n}^{\prime}\right\},\left\{c_{n}^{\prime}\right\}$ are sequences in $[0,1]$ such that $a_{n}+b_{n}+c_{n}=1=a_{n}^{\prime}+b_{n}^{\prime}+c_{n}^{\prime}$, satisfying $\left\{b_{\mathrm{n}}\right\} \subset[\delta, 1-\delta]$ for some $\delta \in(0,1)$ and

$\lim _{n \rightarrow \infty} c_{n}=0=\lim _{n \rightarrow \infty} c_{n}^{\prime}$ And $\left\{u_{n}\right\}$ and $\left\{v_{n}\right\}$ are bounded sequences in C. If $\left\{x_{n}\right\}$ converges to some point $p \in C$, then $p$ is the common fixed point of $\mathrm{S}$ and $\mathrm{T}$.

Theorem 4.6: [3] Let $X$ be a normed linear space and $C$ be a closed convex subset of $X$ and let $S$, T: $X \rightarrow X$ be selfmappings satisfying (CUK) for all $x, y$ in C. Suppose that $\left\{x_{n}\right\}$ is defined by,

$\mathrm{x}_{0} \in \mathrm{C}, \mathrm{x}_{\mathrm{n}}=\mathrm{a}_{\mathrm{n}} \mathrm{x}_{\mathrm{n}-1}+\mathrm{b}_{\mathrm{n}} \operatorname{STx}_{\mathrm{n}}+\mathrm{c}_{\mathrm{n}} \mathrm{u}_{\mathrm{n}}, \mathrm{n} \geq 1$,

where $\left\{a_{n}\right\},\left\{b_{n}\right\},\left\{c_{n}\right\}$ are sequences in $[0,1]$ such that $a_{n}+b_{n}+c_{n}=1$, satisfying $\left\{b_{n}\right\} \subset[\delta, 1-\delta]$ for some $\delta \in(0,1)$ and $\lim _{n \rightarrow \infty} c_{n}=0$ and $\left\{u_{n}\right\}$ is a bounded sequences in C. If $\left\{x_{n}\right\}$ converges to some point $p \in C$, then $p$ is the common fixed point of $\mathrm{S}$ and $\mathrm{T}$.

In 2006, Arif Rafiq [4] established a general theorem to approximate fixed points of Ciric quasi-contractive operators on a generalized convex metric space through the Mann type iteration process with errors in the sense of Xu [86].

Theorem 4.7: [4] Let $\mathrm{C}$ be a nonempty closed convex subset of a generalized convex metric space $\mathrm{X}$. Let $\mathrm{T}: \mathrm{C} \rightarrow \mathrm{C}$ be operator satisfying the condition

(CR) $d(T x, T y) \leq h \max \left\{d(x, y), \frac{d(x, T x)+d(y, T y)}{2}, d(x, T y), d(y, T x)\right\}$,

$\forall \mathrm{x}, \mathrm{y} \in \mathrm{C} ; 0<\mathrm{h}<1$. Let $\left\{\mathrm{x}_{\mathrm{n}}\right\}$ be iterative process defined as:

$\mathrm{x}_{0} \in \mathrm{C}$,

$\mathrm{x}_{\mathrm{n}+1}=\mathrm{W}\left(\mathrm{x}_{\mathrm{n}}, \mathrm{Tx}_{\mathrm{n}}, \mathrm{u}_{\mathrm{n}} ; \mathrm{a}_{\mathrm{n}}, \mathrm{b}_{\mathrm{n}}, \mathrm{c}_{\mathrm{n}}\right), \mathrm{n} \geq 0$,

where $\left\{a_{n}\right\},\left\{b_{n}\right\},\left\{c_{n}\right\}$ are sequences in $[0,1]$ such that $a_{n}+b_{n}+c_{n}=1$ and $\left\{u_{n}\right\}$ is a bounded sequence in $C$, is called

Xu-Mann [86] type iteration process. If $\sum_{n=1}^{\infty} b_{n}=\infty$ and $c_{n}=o\left(b_{n}\right)$, then $\left\{x_{n}\right\}$ converges strongly to the unique fixed point of $\mathrm{T}$.

I.Beg, M. Abbas and J. Kyu Kim [24], in 2006 studied the convergence problem of Mann and Ishikawa type iterative schemes of weakly contractive mapping in a complete convex metric space. They established the results on invariant approximation for the mapping defined on a class of nonconvex sets in a convex metric space and also obtained the existence of common fixed points of two asymptotically mappings through the convergence of iteratively defined sequence in a uniformly convex metric spaces. Results are as follows:

Theorem 4.8: [24] Let $\mathrm{K}$ be a nonempty closed convex subset of a complete convex metric space (X,d) and T be a weakly contractive self-mapping on $\mathrm{K}$. Let $\left\{\mathrm{x}_{\mathrm{n}}\right\}$ be the iterative scheme defined by

$$
\left\{\begin{array}{l}
x_{0} \in K, \\
x_{n+1}=W\left(x_{n}, T\left(x_{n}\right), \alpha_{n}\right), \quad n \geq 0,
\end{array}\right.
$$


where $0 \leq \alpha_{n} \leq 1$ and $\sum \alpha_{n}=\infty$. Then, $\lim _{n \rightarrow \infty} d\left(x_{n}, p\right)=0$, where $p$ is the unique fixed point of $T$.

Theorem 4.9: [24] Let $\mathrm{K}$ be a nonempty closed convex subset of a complete convex metric space (X,d) and $\mathrm{T}$ be a weakly contractive self-mapping on $\mathrm{K}$. Let $\left\{\mathrm{x}_{\mathrm{n}}\right\}$ be the iterative scheme defined by

$$
\left\{\begin{array}{l}
x_{0} \in K, \\
x_{n+1}=W\left(x_{n}, T\left(y_{n}\right), \alpha_{n}\right) \\
y_{n}=W\left(x_{n}, T\left(x_{n}\right), \beta_{n}\right), \quad n \geq 0,
\end{array}\right.
$$

where $0 \leq \alpha_{n}, \beta_{n} \leq 1$, and $\sum \alpha_{n} \beta_{n}=\infty$. Then $\lim _{n \rightarrow \infty} d\left(x_{n}, p\right)=0$, where $p$ is the unique fixed point of $T$.

Theorem 4.10: [24] Let $M$ be a subset of a strictly convex metric space $X$ and $T: M \rightarrow M$ a mapping. If $P_{M}(u)$ is a nonempty T-regular set for any $\mathrm{u} \in \mathrm{X}$, then each point of $\mathrm{P}_{\mathrm{M}}(\mathrm{u})$ is a fixed point of $\mathrm{T}$.

Theorem 4.11: [24] Let $M$ be a nonempty closed and T-regular subset of a strictly convex metric space $X$, where $T$ is a compact mapping on $M$, and $u$ be a point in $M$. Suppose that $d(T(x), u) \leq d(x, u)$ for all $x$ in $M$. Then each $x$ in $\mathrm{M}$, which is the best approximation to $\mathrm{u}$, is a fixed point of $\mathrm{T}$.

Theorem 4.12: [24] Let $M$ be a nonempty closed and T-regular subset of a strictly convex metric space $X$, where $T$ is a compact mapping. Let $\mathrm{u}$ be a fixed point of $\mathrm{T}$ in $\mathrm{X} \backslash \mathrm{M}$, and

$$
\begin{gathered}
\mathrm{d}(\mathrm{T}(\mathrm{x}), \mathrm{T}(\mathrm{y})) \leq \alpha \mathrm{d}(\mathrm{x}, \mathrm{y})+\beta(\mathrm{d}(\mathrm{x}, \mathrm{T}(\mathrm{x}))+\mathrm{d}(\mathrm{y}, \mathrm{T}(\mathrm{y}))) \\
+\gamma(\mathrm{d}(\mathrm{x}, \mathrm{T}(\mathrm{y}))+\mathrm{d}(\mathrm{y}, \mathrm{T}(\mathrm{x})))
\end{gathered}
$$

For all $\mathrm{x}, \mathrm{y} \in \mathrm{X}$, were $\alpha, \beta$ and $\gamma$ are real numbers with $\alpha+2 \beta+\gamma \leq 1$. then each best approximation in $\mathrm{M}$ to $\mathrm{u}$ is a fixed point of $\mathrm{T}$.

Theorem 4.13: [24] Let $\mathrm{K}$ be a nonempty compact and convex subset of a uniformly convex complete metric space $\mathrm{X}$. let $\mathrm{S}, \mathrm{T}: \mathrm{K} \rightarrow \mathrm{K}$ be two mappings satisfying

$\mathrm{d}\left(\mathrm{S}^{\mathrm{n}}(\mathrm{x}), \mathrm{S}^{\mathrm{n}}(\mathrm{y})\right) \leq \mathrm{k}_{\mathrm{n}} \mathrm{d}(\mathrm{x}, \mathrm{y})$ And $\mathrm{d}\left(\mathrm{T}^{\mathrm{n}}(\mathrm{x}), \mathrm{T}^{\mathrm{n}}(\mathrm{y})\right) \leq \mathrm{k}_{\mathrm{n}} \mathrm{d}(\mathrm{x}, \mathrm{y})$

for $n=1,2 \ldots$, where $\left\{\mathrm{k}_{\mathrm{n}}\right\}$ is the sequence of numbers with $1 \leq \mathrm{k}_{\mathrm{n}}<\infty$, for each $\mathrm{n}$, and $\sum_{\mathrm{n}=1}^{\infty}\left(\mathrm{k}_{\mathrm{n}}-1\right)<\infty$. Let $\left\{\mathrm{x}_{\mathrm{n}}\right\}$ be defined as,

$$
\left\{\begin{array}{l}
x_{1} \in K, \\
x_{n+1}=W\left(S^{n}\left(y_{n}\right), x_{n}, \alpha_{n}\right), \\
y_{n}=W\left(T^{n}\left(x_{n}\right), x_{n}, \beta_{n}\right), \quad n \geq 0,
\end{array}\right.
$$

where, $\left\{\alpha_{n}\right\}$ and $\left\{\beta_{n}\right\}$ are sequences of real numbers in $[\varepsilon, 1-\varepsilon]$ for some $\varepsilon \in(0,1)$. Let $\mathrm{p}$ be a common fixed point of $S$ and T. Then, $\lim _{n \rightarrow \infty} d\left(x_{n}, p\right)=0$. That is, the iterative scheme $\left\{x_{n}\right\}$ is convergent to a common fixed point $p$ of $S$ and $\mathrm{T}$.

Later, in the year 2009, T. You-Xian and Y. Chun-de [83] proved some convergence theorems for Noor-typeiterative procedure with errors involving a finite family of uniformly quasi-Lipschitzian mappings in convex metric spaces.

Let $(\mathrm{X}, \mathrm{d})$ be a metric space. A mapping $\mathrm{T}: \mathrm{E} \rightarrow \mathrm{E}$ is said to be uniformly quasi-Lipschitzian, if there exists $\mathrm{L}>0$ such that

$\mathrm{d}\left(\mathrm{T}^{\mathrm{n}} \mathrm{x}, \mathrm{p}\right) \leq \mathrm{Ld}(\mathrm{x}, \mathrm{p}), \quad \forall \mathrm{x} \in \mathrm{X}, \mathrm{p} \in \mathrm{F}(\mathrm{T}), \mathrm{n} \geq 0$.

Theorem 4.14: [83] Let $(X, d)$ be a complete convex metric space and $C$ be a nonempty closed convex subset of $X$. Let $\mathrm{T}_{\mathrm{i}}: \mathrm{C} \rightarrow \mathrm{C}$ be a finite family of uniformly quasi-Lipschitzian mapping for $\mathrm{i}=1,2, \ldots, \mathrm{N}$ such that $\mathrm{F}=\bigcap_{\mathrm{i}=1}^{\mathrm{N}} \mathrm{F}\left(\mathrm{T}_{\mathrm{i}}\right) \neq \phi$ and $\mathrm{f}: \mathrm{C} \rightarrow \mathrm{C}$ be a contractive mapping with a contractive constant $\xi \in(0,1)$. Let $\left\{\mathrm{x}_{\mathrm{n}}\right\}$ be the Noor iterative sequence with errors defined as:

$$
\begin{aligned}
& \mathrm{x}_{\mathrm{n}+1}=\mathrm{W}\left(\mathrm{x}_{\mathrm{n}}, \mathrm{T}_{\mathrm{n}}^{\mathrm{n}} \mathrm{y}_{\mathrm{n}}, \mathrm{u}_{\mathrm{n}} ; \alpha_{\mathrm{n}}, \beta_{\mathrm{n}}, \gamma_{\mathrm{n}}\right), \quad \mathrm{n} \geq 0, \\
& \mathrm{y}_{\mathrm{n}}=\mathrm{W}\left(\mathrm{f}\left(\mathrm{x}_{\mathrm{n}}\right), \mathrm{T}_{\mathrm{n}}^{\mathrm{n}} \mathrm{z}_{\mathrm{n}}, \mathrm{v}_{\mathrm{n}} ; \mathrm{a}_{\mathrm{n}}, \mathrm{b}_{\mathrm{n}}, \mathrm{c}_{\mathrm{n}}\right),
\end{aligned}
$$


$\mathrm{z}_{\mathrm{n}}=\mathrm{W}\left(\mathrm{f}\left(\mathrm{x}_{\mathrm{n}}\right), \mathrm{T}_{\mathrm{n}}^{\mathrm{n}} \mathrm{x}_{\mathrm{n}}, \mathrm{w}_{\mathrm{n}} ; \mathrm{d}_{\mathrm{n}}, \mathrm{e}_{\mathrm{n}}, \mathrm{f}_{\mathrm{n}}\right)$.

where $T_{n}^{n}=T_{n(\bmod N)}^{n}$ is a Lipschitz continuous mapping with a Lipschitz constant $\xi>0$ and $\left\{u_{n}\right\},\left\{v_{n}\right\},\left\{w_{n}\right\}$ be three bounded sequences in $C$ and $\left\{\alpha_{n}\right\},\left\{\beta_{n}\right\},\left\{\gamma_{n}\right\},\left\{a_{n}\right\},\left\{b_{n}\right\},\left\{c_{n}\right\},\left\{d_{n}\right\},\left\{e_{n}\right\},\left\{f_{n}\right\}$ be nine sequences in [0,1] satisfying the following conditions:

i) $\quad \alpha_{n}+\beta_{n}+\gamma_{n}=a_{n}+b_{n}+c_{n}=d_{n}+e_{n}+f_{n}=1, \quad \forall n \geq 0$,

ii) $\sum_{\mathrm{n}=0}^{\infty}\left(\beta_{\mathrm{n}}+\gamma_{\mathrm{n}}\right)<\infty$,

iii) $\quad \mathrm{M}_{0}=\operatorname{Sup}_{\mathrm{p} \in \mathrm{F}, \mathrm{n} \geq 0}\left\{\mathrm{~d}\left(\mathrm{u}_{\mathrm{n}}, \mathrm{p}\right)+\mathrm{d}\left(\mathrm{v}_{\mathrm{n}}, \mathrm{p}\right)+\mathrm{d}\left(\mathrm{w}_{\mathrm{n}}, \mathrm{p}\right)+\mathrm{d}(\mathrm{f}(\mathrm{p}), \mathrm{p})\right\}<\infty$.

Then the sequence $\left\{x_{n}\right\}$ converges to a common fixed point $p \in F$ if and only if $\liminf _{n \rightarrow \infty} d\left(x_{n}, F\right)=0$, where $\mathrm{d}(\mathrm{x}, \mathrm{F})=\inf \{\mathrm{d}(\mathrm{x}, \mathrm{F}), \mathrm{p} \in \mathrm{F}\}$.

Theorem 4.15: [83] Let $(\mathrm{X}, \mathrm{d})$ be a complete convex metric space and $\mathrm{C}$ be a nonempty closed convex subset of $\mathrm{X}$. Let $\mathrm{T}_{\mathrm{i}}: \mathrm{C} \rightarrow \mathrm{C}$ be a finite family of uniformly quasi-Lipschitzian mapping for $\mathrm{i}=1,2, \ldots, \mathrm{N}$ such that $\mathrm{F}=\bigcap_{\mathrm{i}=1}^{\mathrm{N}} \mathrm{F}\left(\mathrm{T}_{\mathrm{i}}\right) \neq \phi$ Let $\left\{\mathrm{x}_{\mathrm{n}}\right\}$ be the iterative sequence with errors defined as:

$\mathrm{x}_{\mathrm{n}+1}=\mathrm{W}\left(\mathrm{x}_{\mathrm{n}}, \mathrm{T}_{\mathrm{n}}^{\mathrm{n}} \mathrm{y}_{\mathrm{n}}, \mathrm{u}_{\mathrm{n}} ; \alpha_{\mathrm{n}}, \beta_{\mathrm{n}}, \gamma_{\mathrm{n}}\right), \quad \mathrm{n} \geq 0$,

$\mathrm{y}_{\mathrm{n}}=\mathrm{W}\left(\mathrm{x}_{\mathrm{n}}, \mathrm{T}_{\mathrm{n}}^{\mathrm{n}} \mathrm{z}_{\mathrm{n}}, \mathrm{v}_{\mathrm{n}} ; \mathrm{a}_{\mathrm{n}}, \mathrm{b}_{\mathrm{n}}, \mathrm{c}_{\mathrm{n}}\right)$,

$\mathrm{z}_{\mathrm{n}}=\mathrm{W}\left(\mathrm{x}_{\mathrm{n}}, \mathrm{T}_{\mathrm{n}}^{\mathrm{n}} \mathrm{x}_{\mathrm{n}}, \mathrm{w}_{\mathrm{n}} ; \mathrm{d}_{\mathrm{n}}, \mathrm{e}_{\mathrm{n}}, \mathrm{f}_{\mathrm{n}}\right)$.

where $\mathrm{T}_{\mathrm{n}}^{\mathrm{n}}=\mathrm{T}_{\mathrm{n}(\bmod )}^{\mathrm{n}}$ is a Lipschitz continuous mapping with a Lipschitz constant $\xi>0$ and $\left\{\mathrm{u}_{\mathrm{n}}\right\},\left\{\mathrm{v}_{\mathrm{n}}\right\},\left\{\mathrm{w}_{\mathrm{n}}\right\}$ be three bounded sequences in $\mathrm{C}$ and $\left\{\alpha_{\mathrm{n}}\right\},\left\{\beta_{\mathrm{n}}\right\},\left\{\gamma_{\mathrm{n}}\right\},\left\{\mathrm{a}_{\mathrm{n}}\right\},\left\{\mathrm{b}_{\mathrm{n}}\right\},\left\{\mathrm{c}_{\mathrm{n}}\right\},\left\{\mathrm{d}_{\mathrm{n}}\right\},\left\{\mathrm{e}_{\mathrm{n}}\right\},\left\{\mathrm{f}_{\mathrm{n}}\right\}$ be nine sequences in $[0,1]$ satisfying the conditions (i)-(iii) of Theorem 4.14.

Then the sequence $\left\{x_{n}\right\}$ converges to a common fixed point $p \in F$ if and only if $\liminf _{n \rightarrow \infty} d\left(x_{n}, F\right)=0$, where $\mathrm{d}(\mathrm{x}, \mathrm{F})=\inf \{\mathrm{d}(\mathrm{x}, \mathrm{F}), \mathrm{p} \in \mathrm{F}\}$.

Theorem 4.16: [83] Let $(X, d)$ be a complete convex metric space and $C$ be a nonempty closed convex subset of $X$. Let $T_{i}: C \rightarrow C$ be a finite family of uniformly quasi-Lipschitzian mapping for $i=1,2, \ldots, N$ such that $\mathrm{F}=\bigcap_{\mathrm{i}=1}^{\mathrm{N}} \mathrm{F}\left(\mathrm{T}_{\mathrm{i}}\right) \neq \phi$ and $\mathrm{f}: \mathrm{C} \rightarrow \mathrm{C}$ be a contractive mapping with a contractive constant $\xi \in(0,1)$. Let $\left\{\mathrm{x}_{\mathrm{n}}\right\}$ be the iterative sequence with errors defined as:

$x_{n+1}=W\left(f\left(x_{n}\right), T_{n}^{n} y_{n}, u_{n} ; \alpha_{n}, \beta_{n}, \gamma_{n}\right), \quad n \geq 0$,

$\mathrm{y}_{\mathrm{n}}=\mathrm{W}\left(\mathrm{f}\left(\mathrm{x}_{\mathrm{n}}\right), \mathrm{T}_{\mathrm{n}}^{\mathrm{n}} \mathrm{x}_{\mathrm{n}}, \mathrm{v}_{\mathrm{n}} ; \mathrm{a}_{\mathrm{n}}, \mathrm{b}_{\mathrm{n}}, \mathrm{c}_{\mathrm{n}}\right)$.

where $T_{n}^{n}=T_{n(\bmod N)}^{n}$ is a Lipschitz continuous mapping with a Lipschitz constant $\xi>0$ and $\left\{\mathrm{u}_{\mathrm{n}}\right\},\left\{\mathrm{v}_{\mathrm{n}}\right\}$ be two bounded sequences in $C$ and $\left\{\alpha_{n}\right\},\left\{\beta_{n}\right\},\left\{\gamma_{n}\right\},\left\{a_{n}\right\},\left\{b_{n}\right\},\left\{c_{n}\right\}$ be six sequences in [0,1] satisfying the conditions (ii) and (iii) of Theorem 4.14 and $\alpha_{n}+\beta_{n}+\gamma_{n}=a_{n}+b_{n}+c_{n}=1$ for all $n \geq 0$.

Then the sequence $\left\{x_{n}\right\}$ converges to a common fixed point $p \in F$ if and only if $\liminf _{n \rightarrow \infty} d\left(x_{n}, F\right)=0$, where $\mathrm{d}(\mathrm{x}, \mathrm{F})=\inf \{\mathrm{d}(\mathrm{x}, \mathrm{F}), \mathrm{p} \in \mathrm{F}\}$.

Theorem 4.17: [83] Let $(X, d)$ be a complete convex metric space and $C$ be a nonempty closed convex subset of $X$. Let $T_{i}: C \rightarrow C$ be a finite family of quasi-nonexpansive mapping for $i=1,2, \ldots, N$ such that $F=\bigcap_{i=1}^{N} F\left(T_{i}\right) \neq \phi$ and $\mathrm{f}: \mathrm{C} \rightarrow \mathrm{C}$ be a contractive mapping with a contractive constant $\xi \in(0,1)$. Let $\left\{\mathrm{x}_{\mathrm{n}}\right\}$ be the iterative sequence with errors defined as in Theorem 4.14 and $\left\{\mathrm{u}_{\mathrm{n}}\right\},\left\{\mathrm{v}_{\mathrm{n}}\right\},\left\{\mathrm{w}_{\mathrm{n}}\right\}$ be three bounded sequences in $\mathrm{C}$ and $\left\{\alpha_{n}\right\},\left\{\beta_{n}\right\},\left\{\gamma_{n}\right\},\left\{a_{n}\right\},\left\{b_{n}\right\},\left\{c_{n}\right\},\left\{d_{n}\right\},\left\{e_{n}\right\},\left\{f_{n}\right\}$ be nine sequences in [0,1] satisfying the conditions (i) (iii) of Theorem 4.14 .

Then the sequence $\left\{x_{n}\right\}$ converges to a common fixed point $p \in F$ if and only if $\liminf _{n \rightarrow \infty} d\left(x_{n}, F\right)=0$, where $\mathrm{d}(\mathrm{x}, \mathrm{F})=\inf \{\mathrm{d}(\mathrm{x}, \mathrm{F}), \mathrm{p} \in \mathrm{F}\}$.

Theorem 4.18: [83] let $(\mathrm{X}, \mathrm{d})$ be a complete convex metric space and $\mathrm{C}$ be a nonempty closed convex subset of $\mathrm{X}$.

Let $T_{i}: C \rightarrow C$ be a finite family of quasi-nonexpansive mapping for $i=1,2, \ldots, N$ such that $F=\bigcap_{i=1}^{N} F\left(T_{i}\right) \neq \phi$. Let $\left\{x_{n}\right\}$ be the iterative sequence with errors defined as in Theorem 4.15 and $\left\{u_{n}\right\},\left\{v_{n}\right\},\left\{w_{n}\right\}$ be three bounded 
sequences in $\mathrm{C}$ and $\left\{\alpha_{n}\right\},\left\{\beta_{n}\right\},\left\{\gamma_{n}\right\},\left\{a_{n}\right\},\left\{b_{n}\right\},\left\{c_{n}\right\},\left\{d_{n}\right\},\left\{e_{n}\right\},\left\{f_{n}\right\}$ be nine sequences in $[0,1]$ satisfying the conditions (i)-(iii) of Theorem 4.14.Then the sequence $\left\{x_{n}\right\}$ converges to a common fixed point $p \in F$ if and only if $\liminf _{n \rightarrow \infty} d\left(x_{n}, F\right)=0$, where $d(x, F)=\inf \{d(x, F), p \in F\}$.

In 2010, Z. Xue, Guiwen Lv, and B.E. Rhoades [82] showed the equivalence of the convergence of Picard and Krasnoselskij, Mann, and Ishikawa iterations for the quasi-contraction mappings in convex metric spaces.

Theorem 4.19: [82] Let $(\mathrm{E}, \mathrm{d}, \mathrm{W})$ be a convex metric space, $\mathrm{T}: \mathrm{E} \rightarrow \mathrm{E}$ a quasi-contraction mapping with $\mathrm{F}(\mathrm{T}) \neq \phi$ Suppose that $\left\{\mathrm{p}_{\mathrm{n}}\right\}_{\mathrm{n}=0}^{\infty},\left\{\mathrm{v}_{\mathrm{n}}\right\}_{\mathrm{n}=0}^{\infty}$ are defined by the iterative processes (1) and (2) given as:

$\forall \mathrm{p}_{0} \in \mathrm{E}, \quad \mathrm{p}_{\mathrm{n}+1}=\mathrm{Tp}_{\mathrm{n}}=\mathrm{T}^{\mathrm{n}+1} \mathrm{p}_{0}, \quad \mathrm{n} \geq 0$

$\forall \mathrm{v}_{0} \in \mathrm{E}, \quad \mathrm{v}_{\mathrm{n}+1}=\mathrm{W}\left(\mathrm{v}_{\mathrm{n}}, \mathrm{Tv}_{\mathrm{n}} ; 1-\lambda, \lambda\right), \quad \mathrm{n} \geq 0$, where $\lambda \in[0,1]$.

Then the following two assertions are equivalent:

i) Picard iteration (4.1.3) converges strongly to the unique fixed point $q \in F(T)$;

ii) Krasnoselskij iteration (4.1.4) converges strongly to the unique fixed point $q \in F(T)$.

Theorem 4.20: [82] Let $(E, d, W), T, F(T)$ be as in Theorem 4.19. Suppose that $\left\{u_{n}\right\}_{n=0}^{\infty},\left\{x_{n}\right\}_{n=0}^{\infty}$ are defined by the iteration processes as follows;

$\forall \mathrm{u}_{0} \in \mathrm{E}, \quad \mathrm{u}_{\mathrm{n}+1}=\mathrm{W}\left(\mathrm{u}_{\mathrm{n}}, \mathrm{Tu}_{\mathrm{n}} ; 1-\mathrm{a}_{\mathrm{n}}, \mathrm{a}_{\mathrm{n}}\right), \quad \mathrm{n} \geq 0$, Where $\mathrm{a}_{\mathrm{n}} \in[0,1]$.

And $\forall \mathrm{x}_{0} \in \mathrm{E}$,

$\mathrm{x}_{\mathrm{n}+1}=\mathrm{W}\left(\mathrm{x}_{\mathrm{n}}, \mathrm{Ty}_{\mathrm{n}} ; 1-\mathrm{a}_{\mathrm{n}}, \mathrm{a}_{\mathrm{n}}\right), \quad \mathrm{n} \geq 0$,

$\mathrm{y}_{\mathrm{n}}=\mathrm{W}\left(\mathrm{x}_{\mathrm{n}}, \mathrm{Tx}_{\mathrm{n}} ; 1-\mathrm{b}_{\mathrm{n}}, \mathrm{b}_{\mathrm{n}}\right), \quad \mathrm{n} \geq 0$, Where $\mathrm{a}_{\mathrm{n}}, \mathrm{b}_{\mathrm{n}} \in[0,1]$ for all $\mathrm{n} \geq 0$.

And $\left\{a_{n}\right\}_{n=0}^{\infty},\left\{b_{n}\right\}_{n=0}^{\infty}$ are real sequences in $[0,1]$ such that $\sum_{n=0}^{\infty} a_{n}=\infty$. Then, the following two assertions are equivalent:

i) Mann iteration (4.1.5) converges strongly to the unique fixed point $q \in F(T)$;

ii) Ishikawa iteration (4.1.6) converges strongly to the unique fixed point $q \in F(T)$.

G.S. Saluja and H. K. Nashine [13], in 2010, gave some necessary and sufficient conditions for an implicit iteration process with errors for a finite family of asymptotically quasi-nonexpansive mappings converging to a common fixed of the mappings in convex metric spaces. They proved the results for an implicit iteration as:

Let $(\mathrm{X}, \mathrm{d}, \mathrm{W})$ be a convex metric space with a convex structure $\mathrm{W}$ and let $\mathrm{T}_{1}, \mathrm{~T}_{2}, \ldots \ldots . \mathrm{T}_{\mathrm{N}}: \mathrm{X} \rightarrow \mathrm{X}$ be $\mathrm{N}$ asymptotically quasi-nonexpansive mappings. For any given $\mathrm{x}_{0} \in \mathrm{X}$,

$\mathrm{x}_{\mathrm{n}}=\mathrm{W}\left(\mathrm{x}_{\mathrm{n}-1}, \mathrm{~T}_{\mathrm{n}(\bmod N)}^{\mathrm{n}} \mathrm{x}_{\mathrm{n}}, \mathrm{u}_{\mathrm{n}} ; \alpha_{\mathrm{n}}, \beta_{\mathrm{n}}, \gamma_{\mathrm{n}}\right), \mathrm{n} \geq 1$,

where $\left\{u_{n}\right\}$ is a bounded sequence in $X,\left\{\alpha_{n}\right\},\left\{\beta_{n}\right\},\left\{\gamma_{n}\right\}$ are three sequences in $[0,1]$ such that $\alpha_{n}+\beta_{n}+\gamma_{n}=1$ for $\mathrm{n}=1,2, \ldots$. Is called the implicit iteration process with errors for a finite family of mappings $\mathrm{T}_{\mathrm{i}}(\mathrm{i}=1,2, \ldots . \mathrm{N})$.

Let $\mathrm{T}_{1}, \mathrm{~T}_{2}, \ldots \ldots . \mathrm{T}_{\mathrm{N}}: \mathrm{X} \rightarrow \mathrm{X}$ be $\mathrm{N}$ asymptotically nonexpansive mappings. Then there exists a sequence $\left\{\mathrm{k}_{\mathrm{n}}\right\} \subset[1, \infty)$ with $\mathrm{k}_{\mathrm{n}} \rightarrow 1$ as $\mathrm{n} \rightarrow \infty$ such that

$\mathrm{d}\left(\mathrm{T}_{\mathrm{i}}^{\mathrm{n}} \mathrm{x}, \mathrm{T}_{\mathrm{i}}^{\mathrm{n}} \mathrm{y}\right) \leq \mathrm{k}_{\mathrm{n}} \mathrm{d}(\mathrm{x}, \mathrm{y}), \quad \forall \mathrm{n} \geq 1$,

For all $x, y \in X$ and for each $i=1,2, \ldots . . N$.

They proved the results for an implicit iteration as:

Theorem 4.21: [13] Let $(X, d, W)$ be a complete convex metric space. Let $T_{1}, T_{2}, \ldots \ldots . . T_{N}: X \rightarrow X$ be $N$ asymptotically quasi-nonexpansive mappings. Suppose $F^{*}=\bigcap_{i=1}^{N} F\left(T_{i}\right) \neq \phi$. Let $\left\{u_{n}\right\}$ be a bounded sequence in $X,\left\{\alpha_{n}\right\},\left\{\beta_{n}\right\},\left\{\gamma_{n}\right\}$ be three sequences in $[0,1],\left\{\alpha_{n}\right\} \subset(s, 1-s)$ for some $s \in(0,1)$ and $\left\{k_{n}\right\}$ be the sequences defined by (4.1.8) satisfying the following conditions:

i) $\quad \alpha_{\mathrm{n}}+\beta_{\mathrm{n}}+\gamma_{\mathrm{n}}=1, \quad \forall \mathrm{n} \geq 1$

ii) $\quad \sum_{\mathrm{n}=1}^{\infty}\left(\mathrm{k}_{\mathrm{n}}-1\right)<\infty$;

iii) $\quad \sum_{n=1}^{\infty} \gamma_{n}<\infty$.

Then the implicit iteration process with errors $\left\{x_{n}\right\}$ generated by (4.1.7) converges to a common fixed point of $\left\{\mathrm{T}_{1}, \mathrm{~T}_{2}, \ldots . . \mathrm{T}_{\mathrm{N}}\right\}$ if and only if $\liminf _{n \rightarrow \infty} D_{d}\left(x_{n}, F^{*}\right)=0$. 
where $D_{d}\left(y, F^{*}\right)$ denotes the distance from $y$ to the set $F^{*}$, that is, $D_{d}\left(y, F^{*}\right)=\inf { }_{z \in F^{*}} d(y, z)$.

If $\mathrm{u}_{\mathrm{n}}=0$, in Theorem 4.21 , the following theorem was obtained.

Theorem 4.22: [13] Let $(X, d, W)$ be a complete convex metric space. Let $T_{1}, T_{2}, \ldots \ldots . T_{N}: X \rightarrow X$ be $N$ asymptotically quasi-nonexpansive mappings. Suppose $\mathrm{F}^{*}=\bigcap_{i=1}^{\mathrm{N}} \mathrm{F}\left(\mathrm{T}_{\mathrm{i}}\right) \neq \phi$. Let $\mathrm{x}_{0} \in \mathrm{X}$ and $\left\{\alpha_{\mathrm{n}}\right\},\left\{\beta_{\mathrm{n}}\right\}$ be two sequences in $[0,1]$, $\left\{\mathrm{k}_{\mathrm{n}}\right\}$ be the sequences defined by (4.1.8) and $\left\{\alpha_{\mathrm{n}}\right\} \subset(\mathrm{s}, 1-\mathrm{s})$ for some $\mathrm{s} \in(0,1)$ satisfying the following conditions:

i) $\quad \alpha_{\mathrm{n}}+\beta_{\mathrm{n}}=1, \quad \forall \mathrm{n} \geq 1$;

ii) $\quad \sum_{\mathrm{n}=1}^{\infty}\left(\mathrm{k}_{\mathrm{n}}-1\right)<\infty$.

Then the implicit iteration process $\left\{\mathrm{x}_{\mathrm{n}}\right\}$ generated by (4.1.7) converges to a common fixed point of $\left\{\mathrm{T}_{1}, \mathrm{~T}_{2}, \ldots \ldots \mathrm{T}_{\mathrm{N}}\right\}$ if and only if

$\liminf _{n \rightarrow \infty} D_{d}\left(x_{n}, F^{*}\right)=0$.

Theorem 4.23: [13] Let $(X, d, W)$ be a complete convex metric space. Let $T_{1}, T_{2}, \ldots \ldots . T_{N}: X \rightarrow X$ be $N$ asymptotically quasi-nonexpansive mappings. Suppose $\mathrm{F}^{*}=\bigcap_{i=1}^{N} \mathrm{~F}\left(\mathrm{~T}_{\mathrm{i}}\right) \neq \phi$ and $\mathrm{x}_{0} \in \mathrm{X}$. Let $\left\{\mathrm{u}_{\mathrm{n}}\right\}$ be an arbitrary bounded sequence in $X,\left\{\alpha_{n}\right\},\left\{\beta_{n}\right\},\left\{\gamma_{n}\right\}$ be three sequences in $[0,1]$ satisfying the following conditions:

i) $\quad \alpha_{\mathrm{n}}+\beta_{\mathrm{n}}+\gamma_{\mathrm{n}}=1, \forall \mathrm{n} \geq 1$;

ii) $\quad\left\{\alpha_{\mathrm{n}}\right\} \subset(\mathrm{s}, 1-\mathrm{s})$ for some $\mathrm{s} \in(0,1)$;

iii) $\quad \sum_{\mathrm{n}=1}^{\infty} \gamma_{\mathrm{n}}<\infty$.

Then the implicit iteration process with errors $\left\{x_{n}\right\}$ generated by (4.1.7) converges to a common fixed point of $\left\{\mathrm{T}_{1}, \mathrm{~T}_{2}, \ldots \ldots \mathrm{T}_{\mathrm{N}}\right\}$ if and only if $\liminf _{n \rightarrow \infty} D_{d}\left(x_{n}, F^{*}\right)=0$.

In 2010, Li-Hua Qiu and Si-Sheng Yao [52] considered the strong convergence of the projection type Ishikawa iteration process to a common fixed point of a finite family of I- asymptotically nonexpansive mappings in generalized convex metric spaces.

The Projection type Ishikawa iteration sequence $\left\{x_{n}\right\}$ given by:

Let $(X, d)$ be a metric space with convex structure $W: X^{3} \times I^{3} \rightarrow X$. Let $T_{i}: X \rightarrow X, i \in\{1, \ldots \ldots . N\}, T_{i}$ is $I_{i}-$ asymptotically quasi-nonexpansive mappings, $I_{i}$ is asymptotically nonexpansive. Then an iterative scheme is the sequences of mappings $\left\{x_{n}\right\}$ defined by,

$\mathrm{x}_{\mathrm{n}+1}=\mathrm{W}\left(\mathrm{y}_{\mathrm{n}}, \mathrm{I}_{\mathrm{i}(\mathrm{n})}^{\mathrm{k}(\mathrm{n})} \mathrm{y}_{\mathrm{n}}, \mathrm{u}_{\mathrm{n}}, \mathrm{a}_{\mathrm{n}}, \mathrm{b}_{\mathrm{n}}, \mathrm{c}_{\mathrm{n}}\right)$,

$\mathrm{y}_{\mathrm{n}}=\mathrm{W}\left(\mathrm{x}_{\mathrm{n}}, \mathrm{T}_{\mathrm{i}(\mathrm{n})}^{\mathrm{k}(\mathrm{n})} \mathrm{x}_{\mathrm{n}}, \mathrm{v}_{\mathrm{n}}, \mathrm{a}_{\mathrm{n}}^{\prime}, \mathrm{b}_{\mathrm{n}}^{\prime}, \mathrm{c}_{\mathrm{n}}^{\prime}\right), \quad \mathrm{n} \geq 1$,

where $\left\{a_{n}\right\},\left\{b_{n}\right\},\left\{c_{n}\right\}\left\{a_{n}^{\prime}\right\},\left\{b_{n}^{\prime}\right\},\left\{c_{n}^{\prime}\right\}$ are real sequences in $(0,1)$ with

$a_{n}+b_{n}+c_{n}=a_{n}^{\prime}+b_{n}^{\prime}+c_{n}^{\prime}=1, n=(k(n)-1) N+i(n), i(n) \in\{1, \ldots, N\} .\left\{u_{n}\right\},\left\{v_{n}\right\}$ are two sequences in $X$ satisfying the following condition: For any non-negative integers $n, m, 0 \geq n<m$, if $\delta\left(A_{n m}\right)>0$, then

$\max _{\mathrm{n} \geq \mathrm{i}, \mathrm{j} \geq \mathrm{m}, 1 \geq \mathrm{k}>\mathrm{N}}\left\{\mathrm{d}(\mathrm{x}, \mathrm{y}): \mathrm{x} \in\left\{\mathrm{u}_{\mathrm{i}}, \mathrm{v}_{\mathrm{i}}\right\}, \mathrm{y} \in\left\{\mathrm{x}_{\mathrm{j}}, \mathrm{y}_{\mathrm{j}}, \mathrm{I}_{\mathrm{k}} \mathrm{y}_{\mathrm{j}}, \mathrm{T}_{\mathrm{k}} \mathrm{x}_{\mathrm{j}}, \mathrm{u}_{\mathrm{j}}, \mathrm{v}_{\mathrm{j}}\right\}\right\}<\delta\left(\mathrm{A}_{\mathrm{nm}}\right)$,

where $A_{n m}=\left\{x_{i}, y_{i}, I_{k} y_{i}, T_{k} x_{i}, u_{i}, v_{i}: n \geq i \geq m, 1 \geq k \geq N\right\}, \delta\left(A_{n m}\right)=\sup _{x, y \in A_{n m}} d(x, y)$. Then $\left\{x_{n}\right\}$ is called the

Projection type Ishikawa iteration process with errors for a finite family of $\mathrm{I}-$ asymptotically nonexpansive mappings $\mathrm{T}_{\mathrm{i}}$.

Theorem 4.24: [52] Let $X$ be a generalized convex metric space, $C$ be a nonempty closed convex subset of $X$, $\left\{\mathrm{T}_{\mathrm{i}}: \mathrm{i} \in\{1, \ldots ., \mathrm{N}\}\right\}: \mathrm{C} \rightarrow \mathrm{C}$ be $\mathrm{N} \mathrm{I}_{\mathrm{i}}$ - asymptotically quasi-nonexpansive mappings with sequences $\left\{\mathrm{v}_{\text {in }}\right\} \subset[0, \infty)$ such that $\sum_{\mathrm{n}=1}^{\infty} \mathrm{v}_{\mathrm{in}}<\infty$ and $\left\{\mathrm{I}_{\mathrm{i}}: \mathrm{i} \in\{1, \ldots ., \mathrm{N}\}\right\}: \mathrm{C} \rightarrow \mathrm{C}$ be $\mathrm{N}$ asymptotically nonexpansive mappings with $\left\{\mathrm{u}_{\mathrm{in}}\right\} \subset[0, \infty)$ such that $\sum_{\mathrm{n}=1}^{\infty} \mathrm{u}_{\mathrm{in}}<\infty$ and $\mathrm{F}=\bigcap_{\mathrm{i}=1}^{\mathrm{N}} \mathrm{F}\left(\mathrm{T}_{\mathrm{i}}\right) \cap \mathrm{F}\left(\mathrm{I}_{\mathrm{i}}\right)$. The Projection type Ishikawa iteration sequence $\left\{\mathrm{x}_{\mathrm{n}}\right\}$ is generated by (4.1.9), $\left\{u_{n}\right\},\left\{v_{n}\right\}$ satisfying (4.1.10) and $F \neq \phi$. Then $\left\{x_{n}\right\}$ converges strongly to a common fixed point in $F$ if and only if $\liminf _{n \rightarrow \infty} d\left(x_{n}, F\right)=0$, where $d(x, F)=\inf \{d(x, p): p \in F\}$. 
Theorem 4.25: [52] Let $\mathrm{X}$ be a generalized convex metric space, $\mathrm{C}$ be a nonempty closed convex subset of $\mathrm{X}, \quad\left\{\mathrm{T}_{\mathrm{i}}: \mathrm{i} \in\{1, \ldots \ldots, \mathrm{N}\}\right\}: \mathrm{C} \rightarrow \mathrm{C}$ be $\mathrm{N} \quad \mathrm{I}_{\mathrm{i}}$ - asymptotically quasi-nonexpansive mappings with sequences $\left\{\mathrm{v}_{\text {in }}\right\} \subset[0, \infty),\left\{\mathrm{I}_{\mathrm{i}}: \mathrm{i} \in\{1, \ldots \ldots, \mathrm{N}\}\right\}: \mathrm{C} \rightarrow \mathrm{C}$ be $\mathrm{N}$ asymptotically nonexpansive mappings with $\left\{\mathrm{u}_{\text {in }}\right\} \subset[0, \infty)$ (without the conditions $\sum_{\mathrm{n}=1}^{\infty} \mathrm{u}_{\mathrm{in}}<\infty$ and $\sum_{\mathrm{n}=1}^{\infty} \mathrm{v}_{\mathrm{in}}<\infty$ ) and $\mathrm{F}=\bigcap_{\mathrm{i}=1}^{\mathrm{N}} \mathrm{F}\left(\mathrm{T}_{\mathrm{i}}\right) \cap \mathrm{F}\left(\mathrm{I}_{\mathrm{i}}\right)$. The Projection type Ishikawa iteration sequence $\left\{x_{n}\right\}$ is generated by (4.1.9), $\left\{u_{n}\right\},\left\{v_{n}\right\}$ satisfying (4.1.10). If $F \neq \phi$ and $\sum_{n=1}^{\infty} a_{n}+b_{n}+c_{n}<\infty$, then $\left\{x_{n}\right\}$ converges strongly to a common fixed point in $F$ if and only if $\liminf _{n \rightarrow \infty} d\left(x_{n}, F\right)=0$.

In 2011, G.S. Saluja [12] established some strong convergence theorems of three-step iteration process with errors for approximating common fixed points for a finite family of asymptotically quasi-nonexpansive mappings in the intermediate sense in the setting of convex metric space. The iterative schemes for which the results proved are as:

Let $(\mathrm{E}, \mathrm{d}, \mathrm{W})$ be a convex metric space and $\mathrm{T}_{\mathrm{i}}: \mathrm{E} \rightarrow \mathrm{E}$ be a finite family of asymptotically quasi-nonexpansive mappings in the intermediate sense with $i=1,2, \ldots \ldots, N$. Let $\left\{\alpha_{n}\right\},\left\{\beta_{n}\right\},\left\{\gamma_{n}\right\},\left\{a_{n}\right\},\left\{b_{n}\right\},\left\{c_{n}\right\},\left\{d_{n}\right\},\left\{e_{n}\right\}$ and $\left\{f_{n}\right\}$ be nine sequences in $[0,1]$ with

$\alpha_{\mathrm{n}}+\beta_{\mathrm{n}}+\gamma_{\mathrm{n}}=\mathrm{a}_{\mathrm{n}}+\mathrm{b}_{\mathrm{n}}+\mathrm{c}_{\mathrm{n}}=\mathrm{d}_{\mathrm{n}}+\mathrm{e}_{\mathrm{n}}+\mathrm{f}_{\mathrm{n}}=1, \quad \mathrm{n}=0,1,2, \ldots$

For a given $\mathrm{x}_{0} \in \mathrm{E}$, define a sequence $\left\{\mathrm{x}_{\mathrm{n}}\right\}$ as follows:

$x_{n+1}=W\left(x_{n}, T_{n}^{n} y_{n}, u_{n} ; \alpha_{n}, \beta_{n}, \gamma_{n}\right), n \geq 0$

$y_{n}=W\left(g\left(x_{n}\right), T_{n}^{n} z_{n}, v_{n} ; a_{n}, b_{n}, c_{n}\right)$,

$z_{n}=W\left(g\left(x_{n}\right), T_{n}^{n} x_{n}, w_{n} ; d_{n}, e_{n}, f_{n}\right)$,

where $\mathrm{T}_{\mathrm{n}}^{\mathrm{n}}=\mathrm{T}_{\mathrm{n}(\bmod N)}^{\mathrm{n}}, \mathrm{g}: \mathrm{E} \rightarrow \mathrm{E}$ is a Lipschitz continuous mapping with a Lipschitz constant $\xi<0$ and $\left\{\mathrm{u}_{\mathrm{n}}\right\},\left\{\mathrm{v}_{\mathrm{n}}\right\},\left\{\mathrm{w}_{\mathrm{n}}\right\}$ are any given three sequences in E. Then $\left\{\mathrm{x}_{\mathrm{n}}\right\}$ is called the Noor-type iterative sequence with errors for a finite family of asymptotically quasi-nonexpansive type mappings $\left\{\mathrm{T}_{\mathrm{i}}\right\}_{\mathrm{i}=1}^{\mathrm{N}}$. If $\mathrm{g}=\mathrm{I}$ (the identity mapping on $\mathrm{E}$ in (1.13)), then the sequence $\left\{\mathrm{x}_{\mathrm{n}}\right\}$ defined by (1.13) can be written as follows:

$$
\begin{aligned}
& x_{n+1}=W\left(x_{n}, T_{n}^{n} y_{n}, u_{n} ; \alpha_{n}, \beta_{n}, \gamma_{n}\right), n \geq 0 \\
& y_{n}=W\left(x_{n}, T_{n}^{n} z_{n}, v_{n} ; a_{n}, b_{n}, c_{n}\right), \\
& z_{n}=W\left(x_{n}, T_{n}^{n} x_{n}, w_{n} ; d_{n}, e_{n}, f_{n}\right),
\end{aligned}
$$

If $\mathrm{d}_{\mathrm{n}}=1\left(\mathrm{e}_{\mathrm{n}}=\mathrm{f}_{\mathrm{n}}=0\right)$ for all $\mathrm{n} \geq 0$ in (1.13) can be written as follows:

$$
\begin{aligned}
& x_{n+1}=W\left(x_{n}, T_{n}^{n} y_{n}, u_{n} ; \alpha_{n}, \beta_{n}, \gamma_{n}\right), n \geq 0 \\
& y_{n}=W\left(g\left(x_{n}\right), T_{n}^{n} g\left(x_{n}\right), v_{n} ; a_{n}, b_{n}, c_{n}\right) .
\end{aligned}
$$

Theorem 4.26: [12] Let (E, d, W) be a complete convex metric space and $\mathrm{C}$ be a nonempty closed convex subset of E. Let $\mathrm{T}_{\mathrm{i}}: \mathrm{C} \rightarrow \mathrm{C}$ be a finite family of uniformly L-Lipschitzian asymptotically quasi-nonexpansive mappings in the intermediate sense for $\mathrm{i}=1,2, \ldots \ldots, \mathrm{N}$ such that $\mathrm{F}=\bigcap_{\mathrm{i}=1}^{\mathrm{N}} \mathrm{F}\left(\mathrm{T}_{\mathrm{i}}\right) \neq \phi$ and $\mathrm{g}: \mathrm{C} \rightarrow \mathrm{C}$ a contractive mapping with a contractive constant $\xi \in(0,1)$. Put

$$
\begin{gathered}
G_{n}=\max \left\{\sup _{p \in F, n \geq 0}\left(d\left(T_{n}^{n} x_{n}, p\right)-d\left(x_{n}, p\right)\right) \vee \sup _{p \in F, n \geq 0}\left(d\left(T_{n}^{n} y_{n}, p\right)-d\left(y_{n}, p\right)\right)\right. \\
\left.\vee \sup _{p \in F, n \geq 0}\left(d\left(T_{n}^{n} z_{n}, p\right)-d\left(z_{n}, p\right)\right) \vee 0\right\},
\end{gathered}
$$

such that $\sum_{n=0}^{\infty} G_{n}<\infty$. Let $\left\{x_{n}\right\}$ be the iterative sequence with errors defined by (4.1.12) and $\left\{\mathrm{u}_{\mathrm{n}}\right\},\left\{\mathrm{v}_{\mathrm{n}}\right\},\left\{\mathrm{w}_{\mathrm{n}}\right\}$ be three bounded sequences in $\mathrm{C}$, and $\left\{\alpha_{\mathrm{n}}\right\},\left\{\beta_{\mathrm{n}}\right\},\left\{\gamma_{\mathrm{n}}\right\},\left\{\mathrm{a}_{\mathrm{n}}\right\},\left\{\mathrm{b}_{\mathrm{n}}\right\},\left\{\mathrm{c}_{\mathrm{n}}\right\},\left\{\mathrm{d}_{\mathrm{n}}\right\}, \quad\left\{\mathrm{e}_{\mathrm{n}}\right\}$ and $\left\{\mathrm{f}_{\mathrm{n}}\right\}$ be nine sequences in $[0,1]$ satisfying the following conditions:

i) $\quad \alpha_{n}+\beta_{n}+\gamma_{n}=a_{n}+b_{n}+c_{n}=d_{n}+e_{n}+f_{n}=1, \quad n=0,1,2, \ldots$

ii) $\quad \sum_{n=0}^{\infty}\left(\beta_{n}+\gamma_{n}\right)<\infty$.

Then the sequence $\left\{x_{n}\right\}$ converges strongly to a common fixed point $p$ of the mappings $\left\{T_{i}\right\}_{i=1}^{N}$ if and only if $\liminf _{n \rightarrow \infty} d\left(x_{n}, F\right)=0$, Where $d(x, F)=\inf _{p \in F} d(x, p)$. 
Theorem 4.27: [12] Let $(\mathrm{E}, \mathrm{d}, \mathrm{W})$ be a complete convex metric space and $\mathrm{C}$ be a nonempty closed convex subset of E. Let $\mathrm{T}_{\mathrm{i}}: \mathrm{C} \rightarrow \mathrm{C}$ be a finite family of uniformly L-Lipschitzian asymptotically quasi-nonexpansive mappings in the intermediate sense for $\mathrm{i}=1,2, \ldots ., \mathrm{N}$ such that $\mathrm{F}=\bigcap_{\mathrm{i}=1}^{\mathrm{N}} \mathrm{F}\left(\mathrm{T}_{\mathrm{i}}\right) \neq \phi$ and $\mathrm{g}: \mathrm{C} \rightarrow \mathrm{C}$ a contractive mapping with a contractive constant $\xi \in(0,1)$. Put

$$
\begin{aligned}
G_{n}=\max \left\{\sup _{p \in F, n \geq 0}\right. & \left(d\left(T_{n}^{n} x_{n}, p\right)-d\left(x_{n}, p\right)\right) \vee \sup _{p \in F, n \geq 0}\left(d\left(T_{n}^{n} y_{n}, p\right)-d\left(y_{n}, p\right)\right) \\
& \left.\vee \sup _{p \in F, n \geq 0}\left(d\left(T_{n}^{n} z_{n}, p\right)-d\left(z_{n}, p\right)\right) \vee 0\right\},
\end{aligned}
$$

such that $\sum_{n=0}^{\infty} G_{n}<\infty$. Let $\left\{x_{n}\right\}$ be the iterative sequence with errors defined by (4.1.13) and $\left\{\mathrm{u}_{\mathrm{n}}\right\},\left\{\mathrm{v}_{\mathrm{n}}\right\},\left\{\mathrm{w}_{\mathrm{n}}\right\}$ be three bounded sequences in $\mathrm{C}$, and $\left\{\alpha_{n}\right\},\left\{\beta_{n}\right\},\left\{\gamma_{n}\right\},\left\{\mathrm{a}_{\mathrm{n}}\right\},\left\{\mathrm{b}_{\mathrm{n}}\right\},\left\{\mathrm{c}_{\mathrm{n}}\right\},\left\{\mathrm{d}_{\mathrm{n}}\right\}, \quad\left\{\mathrm{e}_{\mathrm{n}}\right\}$ and $\left\{\mathrm{f}_{\mathrm{n}}\right\}$ be nine sequences in $[0,1]$ satisfying the following conditions:

i) $\quad \alpha_{n}+\beta_{n}+\gamma_{n}=a_{n}+b_{n}+c_{n}=d_{n}+e_{n}+f_{n}=1, \quad n=0,1,2, \ldots$

ii) $\quad \sum_{n=0}^{\infty}\left(\beta_{n}+\gamma_{n}\right)<\infty$.

Then the sequence $\left\{\mathrm{x}_{\mathrm{n}}\right\}$ converges strongly to a common fixed point $\mathrm{p}$ of the mappings $\left\{\mathrm{T}_{\mathrm{i}}\right\}_{\mathrm{i}=1}^{\mathrm{N}}$ if and only if $\liminf d\left(x_{n}, F\right)=0$, Where $d(x, F)=\inf _{p \in F} d(x, p)$.

Theorem 4.28: [12] Let $(\mathrm{E}, \mathrm{d}, \mathrm{W})$ be a complete convex metric space and $\mathrm{C}$ be a nonempty closed convex subset of E. Let $\mathrm{T}_{\mathrm{i}}: \mathrm{C} \rightarrow \mathrm{C}$ be a finite family of uniformly L-Lipschitzian asymptotically quasi-nonexpansive mappings in the intermediate sense for $\mathrm{i}=1,2, \ldots ., \mathrm{N}$ such that $\mathrm{F}=\bigcap_{\mathrm{i}=1}^{\mathrm{N}} \mathrm{F}\left(\mathrm{T}_{\mathrm{i}}\right) \neq \phi$ and $\mathrm{g}: \mathrm{C} \rightarrow \mathrm{C}$ a contractive mapping with a contractive constant $\xi \in(0,1)$. Put

$$
\begin{aligned}
G_{n}=\max \left\{\sup _{p \in F, n \geq 0}\right. & \left(d\left(T_{n}^{n} x_{n}, p\right)-d\left(x_{n}, p\right)\right) \vee \sup _{p \in F, n \geq 0}\left(d\left(T_{n}^{n} y_{n}, p\right)-d\left(y_{n}, p\right)\right) \\
& \left.\vee \sup _{p \in F, n \geq 0}\left(d\left(T_{n}^{n} z_{n}, p\right)-d\left(z_{n}, p\right)\right) \vee 0\right\},
\end{aligned}
$$

such that $\sum_{n=0}^{\infty} G_{n}<\infty$. Let $\left\{x_{n}\right\}$ be the iterative sequence with errors defined by (4.1.14) and $\left\{\mathrm{u}_{\mathrm{n}}\right\},\left\{\mathrm{v}_{\mathrm{n}}\right\},\left\{\mathrm{w}_{\mathrm{n}}\right\}$ be three bounded sequences in $\mathrm{C}$, and $\left\{\alpha_{\mathrm{n}}\right\},\left\{\beta_{\mathrm{n}}\right\},\left\{\gamma_{\mathrm{n}}\right\},\left\{\mathrm{a}_{\mathrm{n}}\right\},\left\{\mathrm{b}_{\mathrm{n}}\right\},\left\{\mathrm{c}_{\mathrm{n}}\right\},\left\{\mathrm{d}_{\mathrm{n}}\right\}, \quad\left\{\mathrm{e}_{\mathrm{n}}\right\}$ and $\left\{\mathrm{f}_{\mathrm{n}}\right\}$ be nine sequences in $[0,1]$ satisfying the following conditions:

i) $\quad \alpha_{\mathrm{n}}+\beta_{\mathrm{n}}+\gamma_{\mathrm{n}}=\mathrm{a}_{\mathrm{n}}+\mathrm{b}_{\mathrm{n}}+\mathrm{c}_{\mathrm{n}}=\mathrm{d}_{\mathrm{n}}+\mathrm{e}_{\mathrm{n}}+\mathrm{f}_{\mathrm{n}}=1, \quad \mathrm{n}=0,1,2, \ldots$

ii) $\quad \sum_{n=0}^{\infty}\left(\beta_{n}+\gamma_{n}\right)<\infty$.

Then the sequence $\left\{\mathrm{x}_{\mathrm{n}}\right\}$ converges strongly to a common fixed point $\mathrm{p}$ of the mappings $\left\{\mathrm{T}_{\mathrm{i}}\right\}_{\mathrm{i}=1}^{\mathrm{N}}$ if and only if $\liminf _{n \rightarrow \infty} d\left(x_{n}, F\right)=0$, Where $d(x, F)=\inf _{p \in F} d(x, p)$.

After that, G. S. Saluja [14] gave necessary and sufficient conditions for strong convergence of implicit iteration process with errors for approximating common fixed point for a finite family of asymptotically quasi-nonexpansive mappings in the intermediate sense in the setting of convex metric spaces.

Let $(\mathrm{E}, \mathrm{d}, \mathrm{W})$ be a convex metric space with a convex structure $\mathrm{W}$ and let $\mathrm{T}_{1}, \mathrm{~T}_{2}, \ldots \mathrm{T}_{\mathrm{N}}: \mathrm{E} \rightarrow \mathrm{E}$ be $\mathrm{N}$ asymptotically quasi-nonexpansive in the intermediate sense mappings. For any given $\mathrm{x}_{0} \in \mathrm{E}$, the iteration process $\left\{\mathrm{x}_{\mathrm{n}}\right\}$ defined by $x_{n}=W\left(x_{n-1}, T_{n(\bmod N)}^{n} x_{n}, u_{n} ; \alpha_{n}, \beta_{n}, \gamma_{n}\right), \quad n \geq 1$

where $\left\{u_{n}\right\}$ is a bounded sequence in $E,\left\{\alpha_{n}\right\},\left\{\beta_{n}\right\},\left\{\gamma_{n}\right\}$ are three sequences in [0,1] such that $\alpha_{n}+\beta_{n}+\gamma_{n}=1$ for $\mathrm{n}=1,2, \ldots$. Iteration process (4.1.15) is called the implicit iteration process with errors for a finite family of mappings $\left\{\mathrm{T}_{\mathrm{i}}\right\}_{\mathrm{i}=1}^{\mathrm{N}}$.

If $\mathrm{u}_{\mathrm{n}}=0$ in (4.1.15) then,

$$
x_{n}=W\left(x_{n-1}, T_{n(\bmod N)}^{n} x_{n} ; \alpha_{n}, \beta_{n}\right), \quad n \geq 1
$$

where $\left\{\alpha_{n}\right\},\left\{\beta_{n}\right\}$ be two sequences in [0,1] such that $\alpha_{n}+\beta_{n}=1$ for $n=1,2, \ldots$. Iteration process $(4.1 .16)$ is called the implicit iteration process for a finite family of mappings $\left\{T_{i}\right\}_{i=1}^{N}$. 
Theorem 4.29: [14] Let $(E, d, W)$ be a complete convex metric space. Let $T_{i}: E \rightarrow E$ be a finite family of asymptotically quasi-nonexpansive in the intermediate sense mappings for $i=1,2, \ldots ., N$ such that $F=\bigcap_{i=1}^{N} F\left(T_{i}\right) \neq \phi$. put

$$
G_{n}=\max \left\{0, \sup _{p \in F, n \geq 1}\left(d\left(T_{n(\bmod N)}^{n} x_{n}, p\right)-d\left(x_{n}, p\right)\right)\right\} .
$$

Assume that $\sum_{n=1}^{\infty} G_{n}<\infty, \sum_{n=1}^{\infty} \gamma_{n}<\infty$ and $\left\{\alpha_{n}\right\} \subset(s, s-1)$ for some $s \in(0,1)$. then the sequence $\left\{x_{n}\right\}$ defined by (4.1.15) has the following conclusions:

1) $\lim _{n \rightarrow \infty} d\left(x_{n}, F\right)$ exists;

2) The sequence $\left\{x_{n}\right\}$ converges strongly to a common fixed point $p$ of the mappings $\left\{T_{i}\right\}_{i=1}^{N}$ if and only if $\liminf _{n \rightarrow \infty} d\left(x_{n}, F\right)=0$, Where $d(x, F)=\inf _{p \in F} d(x, p)$.

Theorem 4.30: [14] Let $(E, d, W)$ be a complete convex metric space. Let $T_{i}: E \rightarrow E$ be a finite family of asymptotically quasi-nonexpansive in the intermediate sense mappings for $\mathrm{i}=1,2, \ldots . ., \mathrm{N}$ such that $F=\mathbf{I}{ }_{i=1}^{N} F\left(T_{i}\right) \neq \phi$. Put

$G_{n}=\max \left\{0, \sup _{p \in F, n \geq 1}\left(d\left(T_{n(\bmod N)}^{n} x_{n}, p\right)-d\left(x_{n}, p\right)\right)\right\}$.

Assume that $\sum_{n=1}^{\infty} G_{n}<\infty, \sum_{n=1}^{\infty} \gamma_{n}<\infty$ and $\left\{\alpha_{n}\right\} \subset(s, s-1)$ for some $s \in(0,1)$. then the sequence $\left\{x_{n}\right\}$ defined by (4.1.16) converges strongly to a common fixed point $p$ of the mappings $\left\{T_{i}\right\}_{i=1}^{N}$ if and only if

$\liminf _{n \rightarrow \infty} d\left(x_{n}, F\right)=0$.

Later on M. O. Olatinwo [37] proved the convergence results for Jungck-Mann and Jungck-Ishikawa iterative processes for two nonself-mappings in a convex metric space setting by employing a general contractive condition and similar results were also deduced for the Mann and Ishikawa iterations. The contractive condition used to prove the results is given as:

Let $(E, d, W)$ be a complete convex metric space and $Y$ a nonempty closed convex subset of $E$. For two nonselfmappings $S, T: Y \rightarrow E$ with $T(Y) \subseteq S(Y)$, where $S(Y)$ is a complete subspace of $E$, there exists $\delta \in[0,1)$ and some $L \geq 0$ such that for all $x, y \in Y$,

$d(T x, T y) \leq \delta d(S x, S y)+L u(x, y)$,

where,

$u(x, y)=\min \{d(S x, T x), d(S y, T y), d(S x, T y), d(S y, T x)$,

$$
\left.\frac{1}{2}[d(S x, T x)+d(S y, T y)], \frac{1}{2}[d(S x, T y), d(S y, T x)]\right\} .
$$

For $x_{0} \in Y$, Jungck-Mann iterative sequence $\left\{S x_{n}\right\}_{n=0}^{\infty} \subset E$ is defined as:

$S x_{n+1}=W\left(S x_{n}, T x_{n}, \alpha_{n}\right), \quad \alpha_{n} \in[0,1]$

For $x_{0} \in Y$, Jungck-Ishikawa iterative sequence $\left\{S x_{n}\right\}_{n=0}^{\infty} \subset E$ is defined as:

$S x_{n+1}=W\left(S x_{n}, T b_{n}, \alpha_{n}\right), S b_{n+1}=W\left(S x_{n}, T x_{n}, \beta_{n}\right), \alpha_{n}, \beta_{n} \in[0,1]$

Theorem 4.31: [37] Let $(E, d, W)$ be a complete convex metric space and $Y$ a nonempty closed convex subset of $E$. suppose that $S, T: Y \rightarrow E$ are nonself-mappings satisfying condition (4.1.18) such that $T(Y) \subseteq S(Y), S(Y)$ a complete subspace of $E$ and $S$ is an injective mapping. Let $C(S, T)$ be the set of coincidence points of $S$ and $T$, with $C(S, T) \neq \phi$. For $x_{0} \in Y$, let $\left\{S x_{n}\right\}_{n=0}^{\infty}$ defined by (4.1.19) be the Jungck-Mann iterative process with $\alpha_{n} \in[0,1]$, such that $0<\alpha \leq \alpha_{n}, \forall n$. Then, the Jungck-Mann iteration $\left\{S x_{n}\right\}_{n=0}^{\infty}$ converges to $p$.

Theorem 4.32: [37] Let $(E, d, W)$ be a complete convex metric space and $Y$ a nonempty closed convex subset of $E$. suppose that $S, T: Y \rightarrow E$ are nonself-mappings satisfying condition (4.1.18) such that $T(Y) \subseteq S(Y), S(Y)$ a complete subspace of $E$ and $S$ is an injective mapping. Let $C(S, T)$ be the set of coincidence points of $S$ and $T$, with $C(S, T) \neq \phi$. For $x_{0} \in Y$, let $\left\{S x_{n}\right\}_{n=0}^{\infty}$ defined by (4.1.20) be the Jungck-Ishikawa iterative process with 
$\alpha_{n}, \beta_{n} \in[0,1]$, such that $0<\alpha \leq \alpha_{n}, 0<\beta \leq \beta_{n}, \forall n$. Then, the Jungck-Ishikawa iteration $\left\{S x_{n}\right\}_{n=0}^{\infty}$ converges to $p$.

Theorem 4.33: [37] Let $(E, d, W)$ be a complete convex metric space and $Y$ a nonempty closed convex subset of $E$. suppose that $T: Y \rightarrow Y$ is a self-mapping satisfying the condition $d(T x, T y) \leq \delta d(x, y)+L v(x, y), \quad \forall x, y \in Y, L \geq 0, \delta \in[0,1)$, where $v(x, y)=\min \{d(x, T x), d(y, T y), d(x, T y), d(y, T x)$,

$$
\left.\frac{1}{2}[d(x, T x)+d(y, T y)], \frac{1}{2}[d(x, T y), d(y, T x)]\right\} .
$$

Let $p$ be a fixed point of $T$. for $x_{0} \in Y$, let $\left\{x_{n}\right\}_{n=0}^{\infty}$ defined by $x_{n+1}=W\left(x_{n}, T x_{n}, \alpha_{n}\right)$,

Be the Mann iterative process with $\alpha_{n} \in[0,1]$, such that $0<\alpha \leq \alpha_{n}, \forall n$. Then, the Mann iteration $\left\{x_{n}\right\}_{n=0}^{\infty}$ converges to $p$.

Theorem 4.34: [37] Let $(E, d, W)$ be a complete convex metric space and $Y$ a nonempty closed convex subset of $E$. suppose that $T: Y \rightarrow Y$ is a self-mapping satisfying the condition $d(T x, T y) \leq \delta d(x, y)+L v(x, y), \quad \forall x, y \in Y, L \geq 0, \delta \in[0,1)$,

Where

$v(x, y)=\min \{d(x, T x), d(y, T y), d(x, T y), d(y, T x)$,

$$
\left.\frac{1}{2}[d(x, T x)+d(y, T y)], \frac{1}{2}[d(x, T y), d(y, T x)]\right\} .
$$

Let $p$ be a fixed point of $T$. for $x_{0} \in Y$, let $\left\{x_{n}\right\}_{n=0}^{\infty}$ defined by $x_{n+1}=W\left(x_{n}, T b_{n}, \alpha_{n}\right), \quad b_{n}=W\left(x_{n}, T x_{n}, \beta_{n}\right)$,

Be the Ishikawa iterative process with $\alpha_{n}, \beta_{n} \in[0,1]$, such that $0<\alpha \leq \alpha_{n}, \quad 0<\beta \leq \beta_{n}, \forall n$. Then, the Ishikawa iteration $\left\{x_{n}\right\}_{n=0}^{\infty}$ converges to $p$.

D. Ariza-Ruiz [10], in 2012 proved several new results about convergence of distinct iterative processes in convex metric spaces. Also he studied the stability results for the Picard iteration in the setting of metric spaces.

Let $\mathrm{D}$ be a nonempty subset of a metric space $(\mathrm{X}, \mathrm{d})$. We say that $T: D \rightarrow X$ is a $\varphi$-quasinonexpansive mapping if $\operatorname{Fix}(T) \neq \phi$ and there exists a function $\varphi: R^{+} \rightarrow R^{+}$such that $d(T x, p) \leq \varphi(d(x, p))$, for all $x \in X, p \in \operatorname{Fix}(T)$.

Here and subsequently, $\Phi$ denotes the family of functions $\varphi: R^{+} \rightarrow R^{+}$such that $\varphi$ is continuous and $\varphi(t)<t$ for all $t>0$.

Theorem 4.35: [10] Let $C$ be a convex subset of a convex metric space $(X, d, W)$. Assume that $T: C \rightarrow C$ is a $\varphi$ quasinonexpansive mapping with $\varphi \in \Phi$. Let $\left\{\alpha_{n}\right\}_{n \in N}$ be a real sequence in $[0,1]$ such that $\left\{\alpha_{n}\right\}_{n \in N}$ converges to some positive real number. Then, for any $x_{0}$ in $X$, the Mann iteration sequence $\left\{x_{n}\right\}_{n \in N}$ defined by $x_{n+1}=W\left(x_{n}, T x_{n} ; 1-\alpha_{n}, \alpha_{n}\right)$ converges to the unique fixed point of $\mathrm{T}$.

Theorem 4.36: [10] Let $\mathrm{C}$ be a convex subset of a convex metric space $(X, d, W)$. Let $T_{i}: C \rightarrow C$ be a finite family of $\varphi_{i}$-quasinonexpansive mappings, $i=1,2, \ldots \ldots . . N$, with $\varphi \in \Phi$ and $\mathbf{I}_{i=1}^{N} \operatorname{Fix}\left(T_{i}\right) \neq \phi$. Let $\left\{\alpha_{n}\right\}_{n \in N}$ be a real sequence in $[0,1]$ such that $\left\{\alpha_{n}\right\}_{n \in N}$ converges to some positive real number. Then, for any $x_{0}$ in $X$, the sequence $\left\{x_{n}\right\}_{n \in N}$ defined by $x_{n+1}=W\left(x_{n}, T_{n(\bmod N)} x_{n} ; 1-\alpha_{n}, \alpha_{n}\right)$ for all $n \in N$, converges to the common fixed point of $\left\{T_{i}\right\}_{i=1}^{N}$. 
Theorem 4.37: [10] Let $\mathrm{C}$ be a convex subset of a convex metric space $(X, d, W)$. Assume that $T: C \rightarrow C$ is a $\varphi$ quasinonexpansive mapping with $\varphi \in \Phi$. Let $\left\{\alpha_{n}\right\}_{n \in N}$ and $\left\{\beta_{n}\right\}_{n \in N}$ be two real sequences in [0,1] such that $\left\{\alpha_{n} \beta_{n}\right\}_{n \in N}$ converges to some positive real number. Then, for any $x_{0}$ in $X$, the Ishikawa iteration sequence $\left\{x_{n}\right\}_{n \in N}$ defined by $x_{n+1}=W\left(x_{n}, T y_{n} ; 1-\alpha_{n}, \alpha_{n}\right)$ for all $n \in N$, $y_{n}=W\left(x_{n}, T x_{n} ; 1-\beta_{n}, \beta_{n}\right)$

converges to the unique fixed point of $\mathrm{T}$.

Theorem 4.38: [10] Let $(X, d)$ be a complete metric space and $T: X \rightarrow X$ be a $\varphi$-quasinonexpansive mapping with $\varphi \in \Phi$. Let $x_{0} \in X$ and $x_{n+1}=T x_{n}, n \in N$, be the Picard iteration. Let $\left\{y_{n}\right\}_{n \in N} \subset X$ and define $\left\{\varepsilon_{n}\right\}_{n \in N}$ by $\varepsilon_{n}=d\left(y_{n+1}, T y_{n}\right)$, For $n \in N$.

If $\sum_{n \in N} \varepsilon_{n}<\infty$, then $\lim _{n \rightarrow \infty} y_{n}=p$. that is, the Picard iteration is almost stable with respect to T.

In 2013, I. Yildirim, S.H. Khan and M. Ozdemir [23] defined iteration for approximating common fixed points of two uniformly quasi Lipschitzian mappings in convex metric spaces. They proved some convergence theorems for asymptotically quasi-nonexpansive mappings without using "the rate of convergence condition" $\sum_{n=0}^{\infty}\left(k_{n}-1\right)<\infty$ associated with such mappings. The results proved by them are:

Theorem 4.39: [23] Let $(X, d)$ be a convex metric space, $E$ be a nonempty closed convex subset of $X$ and $S, T: E \rightarrow E$ be uniformly quasi-Lipschitzian mappings with respective Lipschitz constants $L_{1}>0$ and $L_{2}>0$, Let the sequence $\left\{x_{n}\right\}$ defined as:

$x_{n+1}=W\left(x_{n}, S^{n} x_{n}, T^{n} x_{n} ; a_{n}, b_{n}, c_{n}\right)$

with the sequence $\left\{a_{n}\right\},\left\{b_{n}\right\}$ and $\left\{c_{n}\right\}$ in [0,1] satisfying $a_{n}+b_{n}+c_{n}=1$ and $\sum_{n=0}^{\infty}\left(1-a_{n}\right)<\infty$.

If $F \neq \phi$, then:

1) for all $p \in F$ and for each $n \in N$, $d\left(x_{n+1}, p\right) \leq\left(1+L\left(1-a_{n}\right)\right) d\left(x_{n}, p\right)$,

2) there exists a constant $M>0$ such that, for all $n, m \in N$ and for every $p \in F$, $d\left(x_{n+m}, p\right)<\operatorname{Md}\left(x_{n}, p\right)$.

Theorem 4.40: [23] Let $(X, d)$ be a complete convex metric space, $E$ be a nonempty closed convex subset of $X$ and $S, T: E \rightarrow E$ be uniformly quasi-Lipschitzian mappings $F \neq \phi$. Let the sequence $\left\{x_{n}\right\}$ defined in Theorem 4.39 with the sequence $\left\{a_{n}\right\},\left\{b_{n}\right\}$ and $\left\{c_{n}\right\}$ in [0,1] satisfying $a_{n}+b_{n}+c_{n}=1$ and $\sum_{n=0}^{\infty}\left(1-a_{n}\right)<\infty$.

Then $\left\{x_{n}\right\}$ converges to a fixed point of $S$ and $T$ if and only if $\liminf _{n \rightarrow \infty} d\left(x_{n}, F\right)=0$, where $d(x, F)=\inf \{d(x, p): p \in F\}$.

Theorem 4.41: [23] Let $(X, d)$ be a complete convex metric space, $E$ be a nonempty closed convex subset of $X$ and $S, T: E \rightarrow E$ be asymptotically quasi-nonexpansive mappings with $\left\{k_{n}\right\}$ and $\left\{k_{n}^{\prime}\right\}$ (without the condition $\sum_{n=0}^{\infty}\left(k_{n}-1\right)<\infty$ and $\left.\sum_{n=0}^{\infty}\left(k_{n}^{\prime}-1\right)<\infty\right)$, and $F \neq \phi . \quad$ Let the sequence $\left\{x_{n}\right\}$ defined in Theorem 4.39 with the sequence $\left\{a_{n}\right\},\left\{b_{n}\right\}$ and $\left\{c_{n}\right\}$ in [0,1] satisfying $a_{n}+b_{n}+c_{n}=1$ and $\sum_{n=0}^{\infty}\left(1-a_{n}\right)<\infty$.

Then $\left\{x_{n}\right\}$ converges to a fixed point of $S$ and $T$ if and only if $\liminf _{n \rightarrow \infty} d\left(x_{n}, F\right)=0$. 
Theorem 4.42: [23] Let $(X, d)$ be a complete convex metric space, $E$ be a nonempty closed convex subset of $X$ and $S, T: E \rightarrow E$ be asymptotically nonexpansive mappings with sequence $\left\{k_{n}\right\}$ and $\left\{k_{n}^{\prime}\right\}$ (without the condition $\sum_{n=0}^{\infty}\left(k_{n}-1\right)<\infty$ and $\left.\sum_{n=0}^{\infty}\left(k_{n}^{\prime}-1\right)<\infty\right)$, and $F \neq \phi$. Let the sequence $\left\{x_{n}\right\}$ defined in Theorem 4.39 with the sequence $\left\{a_{n}\right\},\left\{b_{n}\right\}$ and $\left\{c_{n}\right\}$ in $[0,1]$ satisfying $a_{n}+b_{n}+c_{n}=1$ and $\sum_{n=0}^{\infty}\left(1-a_{n}\right)<\infty$.

Then $\left\{x_{n}\right\}$ converges to a fixed point of $S$ and $T$ if and only if $\liminf _{n \rightarrow \infty} d\left(x_{n}, F\right)=0$.

Olatinwo [38], in 2011 obtained some stability results in complete convex metric spaces for self-mappings satisfying certain general contractive conditions. The contractive condition employed in the sequel is given as:

For a mapping $T: X \rightarrow X$, there exists $\delta \in[0,1)$ and $L \geq 0$ such that $\forall x, y \in X$, we have

$d(T x, T y) \leq \delta d(x, y)+\operatorname{Lm}(x, y)$,

where

$m(x, y)=\min \left\{d(x, T x), d(y, T y), d(x, T y), d(y, T x), \frac{1}{2}[d(x, T x)+d(y, T y)], \frac{1}{2}[d(x, T y)+d(y, T x)]\right\}$.

Theorem 4.43: [38] Let $(X, d, W)$ be a complete metric space and $T: X \rightarrow X$ a mapping satisfying contractive condition (4.1.21). Suppose that $T$ has a fixed point $p$. for $x_{0} \in X$, let the Mann iterative scheme $\left\{x_{n}\right\}_{n=0}^{\infty}$ is defined as:

$x_{n+1}=W\left(x_{n}, T x_{n}, \alpha_{n}\right)$,

where $\alpha_{n} \in[0,1]$ such that $0<\alpha \leq \alpha_{n}$. Then the Mann iteration is T-stable.

Theorem 4.44: [38] Let $(X, d, W)$ be a complete metric space and $T: X \rightarrow X$ a mapping satisfying contractive condition (4.1.21). Suppose that $T$ has a fixed point $p$. for $x_{0} \in X$, let the Ishikawa iterative scheme $\left\{x_{n}\right\}_{n=0}^{\infty}$ be defined as:

$x_{n+1}=W\left(x_{n}, T b_{n}, \alpha_{n}\right)$, with $b_{n}=W\left(x_{n}, T x_{n}, \beta_{n}\right)$,

where $\alpha_{n}, \beta_{n} \in[0,1]$ such that $0<\alpha \leq \alpha_{n}, 0<\beta \leq \beta_{n}$. Then the Ishikawa iteration is T-stable.

\section{Convergence results in hyperbolic spaces:}

Kohlenbach [68] has enriched the concept of convex metric spaces as "hyperbolic space". This section contains various results proved in hyperbolic spaces.

In 2012 A. R. Khan, H. Fukhar-ud-din and A. Ahmad Khan [5] proved $\Delta$-convergence as well as strong convergence through a two-step implicit algorithm for two finite families of nonexpansive maps in the more general setup of hyperbolic spaces. The two-step algorithm for two finite families of nonexpansive maps in hyperbolic spaces is as follows:

$x_{n}=W\left(x_{n-1}, T_{n} y_{n}, \alpha_{n}\right)$,

$y_{n}=W\left(x_{n}, S_{n} x_{n}, \beta_{n}\right), \quad n \geq 1$

where $T_{n}=T_{n(\bmod N)}$ and $S_{n}=S_{n(\bmod N)}$ and $\left\{\alpha_{n}\right\}$ and $\left\{\beta_{n}\right\}$ are two sequences in $(0,1)$.

A map $\eta:(0, \infty) \times(0,2] \rightarrow(0,1]$ which provides such a $\delta=\eta(r, \varepsilon)$ for $u, x, y \in X, r>0$ and $\varepsilon \in(0,2]$, is called modulus of uniform convexity of $X . \eta$ is called to be monotone if it decreases with $r$ (for a fixed $\varepsilon$ ).

A sequence $\left\{x_{n}\right\}$ in $(X, d)$ is Fejer monotone with respect to a subset $K$ of $X$ if $d\left(x_{n}, x\right) \leq d\left(x_{n-1}, x\right)$ for all $x \in K$. A map $T: K \rightarrow K \quad$ is semi-compact if any bounded sequence $\left\{x_{n}\right\}$ satisfying $d\left(x_{n}, T x_{n}\right) \rightarrow 0$ as $n \rightarrow \infty$, has a convergent subsequence. $F(T)$ Denotes the set of all fixed points of $T$. Let $\left\{x_{n}\right\}$ be a bounded sequence in a metric space $X$. Define a functional $r\left(.,\left\{x_{n}\right\}\right): X \rightarrow R^{+}$by $r\left(x,\left\{x_{n}\right\}\right)=\limsup d\left(x, x_{n}\right)$ for all $x \in X$. The asymptotic radius of $\left\{x_{n}\right\}$ with respect to $K \subseteq X$ is defined as $r\left(\left\{x_{n}\right\}\right)=\inf \left\{r\left(x,\left\{x_{n}\right\}\right): x \in K\right\}$. 
A point $y \in K$ is called the asymptotic centre of $\left\{x_{n}\right\}$ with respect to $K \subseteq X$ if $r\left(y,\left\{x_{n}\right\}\right) \leq r\left(x,\left\{x_{n}\right\}\right)$ for all $x \in K$. the set of all asymptotic centres of $\left\{x_{n}\right\}$ is denoted by $A\left(\left\{x_{n}\right\}\right)$.

A sequence $\left\{x_{n}\right\}$ is in $X$ is said to $\Delta$-converge to $x \in X$ if $x$ is the unique asymptotic centre of $\left\{u_{n}\right\}$ for every subsequence $\left\{u_{n}\right\}$ of $\left\{x_{n}\right\}$ [88]. In this case, $x$ is the $\Delta-\operatorname{limit}$ of $\left\{x_{n}\right\}$ i.e. $\Delta-\lim _{n} x_{n}=x$.

Let $\mathrm{f}$ be a nondecreasing self-map on $[0, \infty)$ with $\mathrm{f}(0)=0$ and $\mathrm{f}(\mathrm{t})>0$ for all $t \in(0, \infty)$.

Let $\left\{T_{i}: i \in I\right\}$ and $\left\{S_{i}: i \in I\right\}$ be two finite families of nonexpansive self-maps on $\mathrm{K}$ with $F \neq \phi$. Then the two families are said to satisfy:

i) condition (B) on $\mathrm{K}$ if

$d(x, T x) \geq f(d(x, F))$ or $d(x, S x) \geq f(d(x, F))$ For all $x \in K$,

holds for at least one $T \in\left\{T_{i}: i \in I\right\}$ or one $S \in\left\{S_{i}: i \in I\right\}$;

ii) condition $(\mathrm{C})$ on $\mathrm{K}$ if

$\frac{1}{2}\left\{d\left(x, T_{i} x\right)+d\left(x, S_{i} x\right)\right\} \geq f(d(x, F))$ For all $x \in K$.

Theorem 5.1: [5] Let $\mathrm{K}$ be a nonempty closed convex subset of a complete uniformly convex hyperbolic space $\mathrm{X}$ with monotone modulus of uniform convexity $\eta$ and let $\left\{T_{i}: i \in I\right\}$ and $\left\{S_{i}: i \in I\right\}$ be two finite families of nonexpansive self-maps on $\mathrm{K}$ such that $F \neq \phi$. Then the sequence $\left\{x_{n}\right\}$ defined implicitly in (5.1.1), $\Delta$-converges to a common fixed point of $\left\{T_{i}: i \in I\right\}$ and $\left\{S_{i}: i \in I\right\}$.

Theorem 5.2: [5] Let $\mathrm{K}$ be a nonempty closed convex subset of a complete uniformly convex hyperbolic space $\mathrm{X}$ with monotone modulus of uniform convexity $\eta$ and let $\left\{T_{i}: i \in I\right\}$ and $\left\{S_{i}: i \in I\right\}$ be two finite families of nonexpansive self-maps on $\mathrm{K}$ such that $F \neq \phi$. Suppose that a pair of maps $\mathrm{T}$ and $\mathrm{S}$ in $\left\{T_{i}: i \in I\right\}$ and $\left\{S_{i}: i \in I\right\}$ respectively, satisfies condition (B). Then the sequence $\left\{x_{n}\right\}$ defined implicitly in (5.1.1), converges strongly to $p \in F$.

Theorem 5.3: [5] Let $\mathrm{K}$ be a nonempty closed convex subset of a complete uniformly convex hyperbolic space $\mathrm{X}$ with monotone modulus of uniform convexity $\eta$ and let $\left\{T_{i}: i \in I\right\}$ and $\left\{S_{i}: i \in I\right\}$ be two finite families of nonexpansive self-maps on $\mathrm{K}$ such that $F \neq \phi$. Suppose that one of the map in $\left\{T_{i}: i \in I\right\}$ and $\left\{S_{i}: i \in I\right\}$ is semicompact. Then the sequence $\left\{x_{n}\right\}$ defined implicitly in (5.1.1), converges strongly to $p \in F$.

In 2013, an algorithm for two finite families of nonexpansive maps on a hyperbolic space was proposed and analysed by H.Fukhar-ud-din, A. R. Khan, A. Kalsoom and M. A. A. Khan [17]. The algorithm for which convergence results were proved is as follows:

Let $K$ be convex subset of a convex metric space $X$ and $\left\{S_{n}: n \in I\right\}$ and $\left\{T_{n}: n \in I\right\}$ are finite families of nonexpansive self-maps on the convex subset $K$, where $I=\{1,2,3, \ldots . . N\}$, the indexing set. Then the sequence $\left\{x_{n}\right\}_{n=0}^{\infty}$ was defined as:

$x_{n}=W\left(T_{n} x_{n}, W\left(S_{n} x_{n}, x_{n-1}, \frac{\beta_{n}}{1-\alpha_{n}}\right), \alpha_{n}\right)$

where $S_{n}=S_{n(\bmod N)}$ and $T_{n}=T_{n(\bmod N)}, 0<a \leq \alpha_{n}, \beta_{n} \leq b<1$ and satisfy $\alpha_{n}+\beta_{n}<1$.

For finite families $\left\{T_{i}: i \in I\right\}$ and $\left\{S_{i}: i \in I\right\}$ of nonexpansive maps on $K$, set $F=\mathbf{I}_{i=1}^{N}\left(F\left(T_{i}\right) \cap F\left(S_{i}\right)\right) \neq \phi$.

Theorem 5.4: [17] Let $K$ be a closed and convex subset of a uniformly convex hyperbolic space $X$ with monotone modulus of uniform convexity $\eta$ and let $\left\{T_{i}: i \in I\right\}$ and $\left\{S_{i}: i \in I\right\}$ be two finite families of nonexpansive self-maps of $K$ such that $F \neq \phi$. Then the sequence $\left\{x_{n}\right\}$ in (5.1.2), $\Delta$-converges to an element of $F$. 
Theorem 5.5: [17] Let $K$ be a closed and convex subset of a uniformly convex hyperbolic space $X$ with monotone modulus of uniform convexity $\eta$ and let $\left\{T_{i}: i \in I\right\}$ and $\left\{S_{i}: i \in I\right\}$ be two finite families of nonexpansive self-maps of $K$ such that $F \neq \phi$. Then the sequence $\left\{x_{n}\right\}$ in (5.1.2), converges strongly to $p \in F$ if and only if $\liminf _{n \rightarrow \infty} d\left(x_{n}, F\right)=0$.

Also the strong and $\Delta$-convergence theorems for the Ishikawa type algorithm were established for two mutivalued quasi-nonexpansive maps in uniformly convex hyperbolic space by H. Fukhar-ud-din, A. R. Khan and M. Ubaid-UrRehman [18].

A nonempty subset $D$ of a metric space $X$ is called proximinal if for each $x \in X$, there exists an element $y \in D$ such that $d(x, y)=d(x, D)$, where $d(x, D)=\inf \{d(x, z): z \in D\}$. Let $C B(D), K(D)$ and $P(D)$ denote the family of nonempty, closed and bounded subsets; nonempty, compact subsets and nonempty, proximal and bounded subsets of $D$, respectively. Hausdorff metric on $C B(D)$ is defined by:

$H(A, B)=\max \left(\sup _{x \in A} d(x, B), \sup _{y \in B} d(y, A)\right)$

For all $A, B \in C B(D)$.

Let $T_{1}$ and $T_{2}$ be two quasi-nonexpansive multi-valued maps from $D$ into $C B(D)$ where $D$ is a convex subset of a hyperbolic space. Then for $x_{1} \in D$, generate $\left\{x_{n}\right\}$ as

$y_{n}=W\left(z_{n}, W\left(x_{n}, u_{n}, \frac{\beta_{n}}{1-\alpha_{n}}\right), \alpha_{n}\right), n \geq 1$,

$x_{n+1}=W\left(z_{n}, W\left(x_{n}, v_{n}, \frac{\beta_{n}}{1-\alpha_{n}}\right), \alpha_{n}\right), n \geq 1$,

where $z_{n}^{\prime} \in T_{1} x_{n}, z_{n} \in T_{2} y_{n}, 0 \leq \alpha_{n}, \beta_{n}, \alpha_{n}+\beta_{n}, \alpha_{n}^{\prime}, \beta_{n}^{\prime}, \alpha_{n}^{\prime}+\beta_{n}^{\prime} \leq 1,\left\{u_{n}\right\}$ and $\left\{v_{n}\right\}$ are bounded in $D$.

Let $T_{1}$ and $T_{2}$ be two multi-valued maps from $D$ into $P(D)$ and $P_{T_{i}} x=\left\{y \in T_{i} x: d(x, y)=d\left(x, T_{i} x\right)\right\}, i=1,2$. then for $x_{1} \in D$, generate $\left\{x_{n}\right\}$ as

$$
\begin{aligned}
& y_{n}=W\left(z_{n}, W\left(x_{n}, u_{n}, \frac{\beta_{n}^{\prime}}{1-\alpha_{n}^{\prime}}\right), \alpha_{n}^{\prime}\right), n \geq 1, \\
& x_{n+1}=W\left(z_{n}, W\left(x_{n}, v_{n}, \frac{\beta_{n}}{1-\alpha_{n}}\right), \alpha_{n}\right), n \geq 1,
\end{aligned}
$$

where $z_{n}^{\prime} \in P_{T_{1}} x_{n}$ and $z_{n} \in P_{T_{2}} y_{2}, 0 \leq \alpha_{n}, \beta_{n}, \alpha_{n}+\beta_{n}, \alpha_{n}^{\prime}, \beta_{n}^{\prime}, \alpha_{n}^{\prime}+\beta_{n}^{\prime} \leq 1,\left\{u_{n}\right\}$ and $\left\{v_{n}\right\}$ are bounded in $D$.

A multi-valued map $\mathrm{T}: \mathrm{D} \rightarrow \mathrm{CB}(\mathrm{D})$ is said to satisfy condition (I) if there is a nondecreasing function $f:[0, \infty) \rightarrow[0, \infty)$ with $\mathrm{f}(0)=0, \mathrm{f}(\mathrm{t})>0$ for $t \in(0, \infty)$ such that $d(x, T x) \geq f(d(x, F))$ for all $x \in D$.

Two multi-valued maps $T_{1}, T_{2}: D \rightarrow C B(D)$ are said to satisfy condition (II) if there is a nondecreasing function $f:[0, \infty) \rightarrow[0, \infty)$ with $\mathrm{f}(0)=0, \mathrm{f}(\mathrm{r})>0$ for $r \in(0, \infty)$ such that either $d\left(x, T_{1} x\right) \geq f(d(x, F))$ or $d\left(x, T_{2} x\right) \geq f(d(x, F))$ holds for all $x \in D$.

Theorem 5.6: [18] Let $D$ be a nonempty, closed and convex subset of a complete uniformly convex W-hyperbolic space $X$ with monotone modulus of uniform convexity $\eta$ and let $T_{1}$ and $T_{2}$ be two multivalued Lipschitzian quasinonexpansive maps from $D$ into $C B(D)$ with $T_{1} p=\{p\}=T_{2} p$ for all $p \in F \neq \phi$. Then the algorithm $\left\{x_{n}\right\}$ in (5.1.3) with $0<l \leq \alpha_{n}, \alpha_{n}^{\prime} \leq k<1, \sum_{n=1}^{\infty}\left(1-\alpha_{n}-\beta_{n}\right)<\infty$ and $\sum_{n=1}^{\infty}\left(1-\alpha_{n}^{\prime}-\beta_{n}^{\prime}\right)<\infty, \Delta-$ converges to a point in $F$.

Theorem 5.7: [18] Let $D$ be a nonempty, closed and convex subset of a complete uniformly convex W-hyperbolic space $X$ and let $T_{1}, T_{2}$ be two multivalued Lipschitzian quasi-nonexpansive maps from $D$ into $C B(D)$ with 
$F \neq \phi$. Then the algorithm $\left\{x_{n}\right\}$ in (5.1.3) with $\sum_{n=1}^{\infty}\left(1-\alpha_{n}-\beta_{n}\right)<\infty$ and $\sum_{n=1}^{\infty}\left(1-\alpha_{n}^{\prime}-\beta_{n}^{\prime}\right)<\infty$, converges to a point in $F$ if and only if $\liminf _{n \rightarrow \infty} d\left(x_{n}, F\right)=0$.

Theorem 5.8: [18] Let $D$ be a nonempty, closed and convex subset of a complete uniformly convex W-hyperbolic space $X$ and let $T_{1}, T_{2}$ be two multivalued Lipschitzian quasi-nonexpansive maps from $D$ into $C B(D)$ with $F \neq \phi$ and either of the two maps is hemicompact or satisfies Condition (II). Then the algorithm $\left\{x_{n}\right\}$ in (5.1.3) with $0<l \leq \alpha_{n}, \alpha_{n}^{\prime} \leq k<1$, $\sum_{n=1}^{\infty}\left(1-\alpha_{n}-\beta_{n}\right)<\infty$ and $\sum_{n=1}^{\infty}\left(1-\alpha_{n}^{\prime}-\beta_{n}^{\prime}\right)<\infty$, strongly converges to a point in $F$.

Theorem 5.9: [18] Let $D$ be a nonempty, closed and convex subset of a complete uniformly convex W-hyperbolic space $X$ with monotone modulus of uniform convexity $\eta$ and let $T_{1}$ and $T_{2}$ be two multivalued maps from $D$ into $P(D)$ with $F \neq \phi \quad$ such that $P_{T_{1}}$ and $P_{T_{2}}$ are nonexpansive. Then the algorithm $\left\{x_{n}\right\}$ in (5.1.4) with $0<l \leq \alpha_{n}, \alpha_{n}^{\prime} \leq k<1, \sum_{n=1}^{\infty}\left(1-\alpha_{n}-\beta_{n}\right)<\infty$ and $\sum_{n=1}^{\infty}\left(1-\alpha_{n}^{\prime}-\beta_{n}^{\prime}\right)<\infty, \Delta$-converges to a point in $F$.

Theorem 5.10: [18] Let $D$ be a nonempty, closed and convex subset of a complete uniformly convex W-hyperbolic space $X$ and let $T_{1}$ and $T_{2}$ be two multivalued maps from $D$ into $P(D) \quad$ with $\quad F \neq \phi \quad$ such that $\quad P_{T_{1}} \quad$ and $\quad P_{T_{2}} \quad$ are nonexpansive. Then the algorithm $\quad\left\{x_{n}\right\} \quad$ in (5.1.4) with $0<l \leq \alpha_{n}, \alpha_{n}^{\prime} \leq k<1, \sum_{n=1}^{\infty}\left(1-\alpha_{n}-\beta_{n}\right)<\infty$ and $\sum_{n=1}^{\infty}\left(1-\alpha_{n}^{\prime}-\beta_{n}^{\prime}\right)<\infty$, converges strongly to a point in $F$ if and only if $\liminf _{n \rightarrow \infty} d\left(x_{n}, F\right)=0$.

Theorem 5.11: [18] Let $D$ be a nonempty, closed and convex subset of a complete uniformly convex W-hyperbolic space $X$ and let $T_{1}$ and $T_{2}$ be two multivalued maps from $D$ into $P(D) \quad$ with $F \neq \phi \quad$ such that $P_{T_{1}}$ and $P_{T_{2}}$ are nonexpansive. If one of the maps is hemicompact or satisfies Condition (II), then the algorithm $\left\{x_{n}\right\} \quad$ in (5.1.4) with $0<l \leq \alpha_{n}, \alpha_{n}^{\prime} \leq k<1, \sum_{n=1}^{\infty}\left(1-\alpha_{n}-\beta_{n}\right)<\infty$ and $\sum_{n=1}^{\infty}\left(1-\alpha_{n}^{\prime}-\beta_{n}^{\prime}\right)<\infty$, strongly converges to a point in $F$.

Recently, Chugh et. al. [59] proved strong and $\Delta$-convergence theorems of modified S-iterative scheme for asymptotically quasi-nonexpansive mappings in hyperbolic spaces. Modified S-iterative scheme [58] is defined as,

$x_{n+1}=W\left(T^{n} x_{n}, T^{n} y_{n}, \alpha_{n}\right)$,

$y_{n}=W\left(x_{n}, T^{n} x_{n}, \beta_{n}\right), n \in N$

where $\alpha_{n}, \beta_{n} \in[0,1]$.

A mapping $T: C \rightarrow C$, where $C$ is a subset of a Hyperbolic space $E$, is said to satisfy condition (A) [19s], if there exists a nondecreasing function $f:[0, \infty) \rightarrow[0, \infty)$ with $f(0)=0, f(r)>0$ for all $r \in(0, \infty)$ such that $d(x, T x) \geq f(d(x, F(T))$ For all $x \in C$ where $d(x, F(T))=\inf \{d(x, p): p \in F(T)\}$ and $F(T)$ denotes the set of fixed points of $T$.

Theorem 5.12: [59] Let $C$ be a nonempty closed convex subset of a uniformly convex Hyperbolic space $E$. Let $T$ be uniformly Lipschitzian and asymptotically quasi-nonexpansive self-mapping of $C$ with $\sum_{n=1}^{\infty}\left(k_{n}-1\right)<\infty$. Let $\left\{x_{n}\right\}$ be defined by (5.1.5) and $F(T) \neq \phi$. Then $\lim _{n \rightarrow \infty} d\left(x_{n}, T x_{n}\right)=0$. 
Theorem 5.13: [59] Let $E$ be a uniformly convex hyperbolic space and let $C, T$ and $\left\{x_{n}\right\}$ be taken as in Theorem 5.12. If the mapping $I-T$ is demi closed at zero and $F(T) \neq \phi$, then the sequence $\left\{x_{n}\right\}$ in (5.1.5), $\Delta$-converges to a fixed point of $T$.

Theorem 5.14: [59] Let $E$ be a convex hyperbolic space and let $C, T$ and $\left\{x_{n}\right\}$ be taken as in Theorem 5.12. Then $\left\{x_{n}\right\} \quad$ converges to a point of $F(T)$ if and only if $\lim _{n \rightarrow \infty} d\left(x_{n}, F(T)\right)=0$, where $d(x, F(T))=\inf \{d(x, p) ; p \in F(T)\}$.

Theorem 5.15: [59] Let $E$ be a uniformly convex hyperbolic space and let $C, T$ and $\left\{x_{n}\right\}$ be taken as in Theorem 5.12. Let $T$ satisfy the condition (A), then $\left\{x_{n}\right\}$ converges strongly to a fixed point of $T$.

\section{Conclusions}

In this work, we give the different results proved in convex metric spaces. The authors do not claim to provide complete coverage of the literature. In spite of these shortcomings, this paper should be useful for those persons who want to work in this field. Obviously, the present paper enriches our knowledge of fixed point and convergence of various iterative schemes in convex metric spaces.

\section{Acknowledgments}

The authors would like to thank to the referee for his/her careful reading of manuscript and their valuable comments. The second author gratefully acknowledges Council of Scientific \& Industrial Research (CSIR) for providing financial assistance under junior research Fellowship

\section{References}

[1] A. M. Harder and T.L. Hicks, Stability results for fixed point iteration procedures, Math. Japonica, vol. 33 no. 5, (1988), 693-706.

[2] A. Liepins, A cradle-song for a little tiger on fixed points, Topological Spaces and their mappings. Riga, (1983), 61-69.

[3] A. Rafiq and S. Zafar, On the convergence of implicit Ishikawa iterations with errors to a common fixed point of two mappings in convex metric spaces, General Mathematics, vol. 14, no. 2, (2006), 95-108.

[4] A. Rafiq, Fixed point of Ciric quasi-contractive operators in generalized convex metric spaces, General Mathematics, vol. 14, no. 3, (2006), 79-90.

[5] A. R. Khan, H. Fukha-ud-din and M. A. A. Khan, An implicit algorithm for two finite families of nonexpansive maps in hyperbolic spaces, Fixed Point Theory and Applications, vol. 2012, (2012), 1-12.

[6] A. M. Harder and T. L. Hicks, A stable iteration procedure for nonexpansive mappings, Math. Japon., vol.33 no. 5, (1988), 687-692.

[7] B. E. Rhoades, Fixed point theorems and stability results for fixed point iteration procedures II, Indian J. Pure Appl. Math., vol. 24, no. 11, (1993), 691-703.

[8] B. E. Rhoades, Some theorems on weakly contractive maps, Nonlinear Analysis, vol. 47, (2001), $2683-2693$.

[9] C. Wang and L.W. Liu, Convergence theorems of fixed points of uniformly quasi-Lipschitzian mappings in convex metric spaces, Nonlinear Anal, TMA, vol. 70, (2009), 2067-2071.

[10] D. Ariza-Ruiz, Convergence and stability of some iterative processes for a class of quasi nonexpansive type mappings, Journal of Nonlinear Science and Applications, vol. 5, (2012), 93-103.

[11] F. E. Browder, Non expansive nonlinear operators in a Banach space, Proc. Nat. Acad. Sci. USA, vol. 54, (1965), 1041-1044.

[12] G.S Saluja, Three-step iteration process for a finite family of Asymptotically quasi-nonexpansive mappings in the intermediate sense in convex metric spaces, Bulletin of Mathematical Analysis and Applications, vol. 3, (2011), 89-101.

[13] G. S. Saluja and H. K. Nashine, Convergence of implicit iteration process for a finite family of asymptotically Quasi-nonexpansive mappings in convex metric spaces, vol. 30, no. 3, (2010), 331-340.

[14] G. S. Saluja, Approximating common fixed points for asymptotically quasi-non-expansive mappings in the intermediate sense in convex metric spaces, Functional Analysis, Approximation and Computation, vol. 3, no. 1, (2011), 33-44.

[15] G. Jungck, Compatible mappings and common fixed points, Internat J. Math. Math. Sci., vol. 9, (1986), 771-779.

[16] G. Jungck and B.E. Rhoades, Some fixed point theorems for compatible maps, Internat J. Math. Math. Sci., vol. 16, (1993), 417-428.

[17] H. Fukhar-ud-din, A.R. Khan A. Kalsoom and M.A.A. Khan, One step implicit algorithm for two finite families of nonexpansive maps in Hyperbolic spaces, J. Adv. Math. Stud., vol. 6 no. 1, (2013), 73-81.

[18] H. Fukhar-ud-din, A. R. Khan and M. Ubaid-Ur-Rehman, Ishikawa type algorithm of multi-valued Quasi-nonexpansive maps on nonlinear domains, Annals of Functional. Analysis, vol. 4 no. 2, (2013), 97-110.

[19] H. F. Senter and W. G. Doston, Approximating fixed points of nonexpansive mappings, Proc. Amer. Math. Soc., vol. 44, (1974), 375-380.

[20] I. Beg, Inequalities in metric spaces with applications, Topological Methods in Nonlinear Analysis, vol. 17, (2001), 183-190.

[21] I. Beg, An iteration scheme for asymptotically nonexpansive mappings on uniformly convex metric spaces, Nonlinear Analysis Forum, vol. 6, no. 1, (2001), 27-34

[22] I. Bula, Strictly convex metric spaces and fixed points, Mathematica Moravica, vol. 3, (1999), 5-16.

[23] I. Yildirim, S. H. Khan and M. Ozdemir, Some fixed point results for uniformly Quasi-Lipschitzian mappings in convex metric spaces, Journal of Nonlinear Analysis and Optimization, vol. 4, (2013), 143-148. 
[24] I. Beg, M. Abbas and J. K. Kim, Convergence theorems of the iterative schemes in convex metric spaces: Nonlinear Funct. Anal. \& Appl., vol. 11 , no. 3, 421-436.

[25] I. Beg and M. Abbas, Common fixed points and best approximation in convex metric spaces, Soochow Journal of Mathematics, vol. 33, no. 4, (2007), 729-738.

[26] I. Beg, Structure of the set of fixed points of nonexpansive mappings in convex metric spaces, Ann. Univ. Curie-Sklodowska Sec. vol. 52, (1998), 7-14.

[27] J. B. Baillon, Nonexpansive mappings and Hyperconvex spaces, Contemp. Math., vol. 72, (1988), 11-19.

[28] J. P. Penot, Fixed point theorems without convexity, Bull. Soc. Math. France, vol. 60, (1979), 129-152.

[29] K. Geobel and W.A. Kirk, Iteration processes for nonexpansive mapping in topological methods in nonlinear functional Analysis (Toronto, Canada, 1982), American

Mathematical Society of contemporary Mathematics, Providence, RI, USA, and vol. 21, (1983), 115-123.

[30] K. P. R. Sastry, G. V. R. Babu and Ch. Srinivasa Rao, Convergence of Ishikawa iteration scheme for a nonlinear quasi-contractive pair of selfmaps of convex metric spaces, Indian J. pure appl. Math., vol. 33, no. 2, (2002), 203-214.

[31] L.P. Belluce and W.A. Kirk, Fixed-point theorems for families of contraction mappings, Pacific J. Math., vol. 18, (1966), $213-218$.

[32] Lj. B. Ciric, A generalizations of Banach's contraction principle. Proc. Amer. Math.,vol. 45, (1974), $267-273$.

[33] Lj. B. Ciric, on some discontinuous fixed point theorems on convex metric spaces, Czechoslovak Math. J., vol. 43, (1993), 319-326.

[34] Lj. B. Ciric et al, on the convergence of the Ishikawa iterates to a common fixed point of two mappings, Archivum Mathematicum (Brno), Tomus, vol. 39, (2003), 123-127.

[35] M. Edelstein, on nonexpansive mapping of Banach spaces, Proc. Camb. Phil. Soc., vol. 60, (1964), $439-447$.

[36] M.A. Khamsi, M. Lin and R. Sine: On the fixed points of commuting nonexpansive maps in hyperconvex spaces. J. Math. Anal. Appl., vol. $168,(1992), 372-380$.

[37] M. O. Olatinwo, Convergence results for Jungck-type iterative processes in convex metric spaces. Acta Univ. Palacki. Olomuc. Fac. rer. nat., Mathematica, vol. 51, no. 1, (2012), 79-87.

[38] M.O. Olatinwo, Stability results for some fixed point iterative processes in convex metric spaces, Int. journal of engineering, vol. 3, (2011), 103-106.

[39] M. R. Taskovic, General convex topological spaces and fixed points, Math. Moravica, vol. 1, (1997), $127-134$.

[40] M. Lin and R. Sine, on the fixed point set of order preserving maps, Math. Zeit. vol. 203, (1990), 227-234.

[41] M. O. Olatinwo, Convergence and stability results for some iterative schemes, Acta Universities Apulensis, vol. 26, (2011), $225-236$.

[42] M. D. Guay, K. L. Singh and J. H. M. Whitfield, Fixed point theorems for nonexpansive mappings in convex metric spaces, In: S. P.Singh J. H. Barry (eds.) Proceedings of Conference on Nonlinear Analysis, vol. 80, (1982), 179-189.

[43] M. A. Noor, New approximation schemes for general variational inequalities, Journal of Mathematical Analysis and applications, vol. 251, no. 1, (2000), 217-229.

[44] N. Aronszajn and P. Panitchpakdi, Extensions of uniformly continuous transformations and hyperconvex metric spaces, Pac. J. Math., vol. 6, (1956), 405-439.

[45] O. Hadzic, A common fixed point theorem for a family of mappings in convex metric spaces, Univ. u Novom Sadu, vol. 20, (1990), 89-95.

[46] O. Hadzic, Some common fixed point theorems in convex metric spaces, Univ. u Novom Sadu, Zb. Prirod.- Mat. Fak. Ser. Mat., vol. 15, no. 2, (1985), 1-13.

[47] P. Kuhfitting, Fixed points of several classes of non-linear mapping in Banach space, Proc. Amer. Math. Soc., vol. 44, (1974), 300-306.

[48] P. Soardi, Existence of fixed points of nonexpansive mappings in certain Banach lattices, Proc. Am. Math. Soc., vol. 73, (1979), 25-29.

[49] Q. Liu, Iterative sequences for asymptotically quasi-nonexpansive mappings, Journal of Mathematical Analysis and applications, vol. 207, no. 1, (1997), 96-103.

[50] Q. Liu, Iterative sequences for asymptotically quasi-nonexpansive mappings with error member, Journal of Mathematical Analysis and Applications, vol. 259, no. 1, (2001), 18-24.

[51] Q. Liu, Iterative sequences for asymptotically quasi-nonexpansive mapping with an error member of uniform convex Banach space. Journal of Mathematical Analysis and Applications, vol. 266, no. 2, (2002), 468-471.

[52] Q. Li-Hua and Y. Si-Sheng, Convergence of the Projection type Ishikawa iteration process with errors for a finite family of I-Asymptotically non-expansive mappings in Generalized Convex metric spaces, International Mathematical Forum, vol. 5, no. 43, $2010,2103-2109$.

[53] R. Chugh., V. Kumar and S. Kumar, Strong convergence of a new three step Iterative scheme in Banach spaces. American Journal of Computational Mathematics, vol. 2, (2012), 345-357.

[54] R. Sine, Hyperconvexity and approximate fixed points, Nonlinear Anal., vol. 13, (1989), 863-869.

[55] R. Sine, Hyperconvexity and nonexpansive multifunctions, Trans. Am. Math. Soc., vol. 315, (1989), $755-767$.

[56] R. Sine, on nonlinear contraction semigroups in sup norm spaces, Nonlinear Anal., vol. 3, (1979), 885-890.

[57] R. P. Agarwal, D. O'Regan and D. R. Sahu, Fixed point theory for Lipschitzian-type mappings with applications, Topological Fixed Point Theory and Its Applications, vol. 6, (2009).

[58] R. P. Agarwal, D. O'Regan and D. R. Sahu, Iterative construction of fixed points of nearly asymptotically nonexpansive mapping, Journal of Nonlinear and convex Analysis, vol.8, no. 1, (2007), 61-79.

[59] R. Chugh, Preety and M. Aggarwal, Some convergence results for modified S-iterative scheme in Hyperbolic spaces, International Journal of Computer Applications, vol. 80, no. 6, (2013), 20-23

[60] S. Sharma and B. Deshpande, Common fixed point theorems of Gregus type in convex metric spaces, Mathematica Moravica, vol. 6, (2002), $77-85$.

[61] S. Sharma and B. Deshpande, Discontinuity and weak compatibility in fixed point consideration of Gregus type in convex metric spaces, Fasciculi Mathematici, vol. 36, (2005), 91-100.

[62] S. A. Naimpally and K. L. Singh, Extensions of some fixed point theorems of Rhoades, J. Math. Anal. Appl., vol. 96, (1983), 437-446.

[63] S. Ishikawa, Fixed point by a new iteration method, Proc. Amer. Math. Soc., vol. 44, no. 1, (1974), $147-150$.

[64] S. S. Chang, J. K. Kim and D. S. Jin, Iterative sequences with errors for asymptotically quasi-nonexpansive type mappings in convex metric spaces, Archives of inequality and Applications, vol. 2, (2004), 365-374.

[65] T. Shimizu and W. Takahashi, Fixed point theorems in certain convex metric spaces, Math. Japon., vol. 37, (1992), 855-859.

[66] T. Shimizu and W. Takahashi, Fixed points of multivalued mappings in certain convex metric spaces, Topological Methods in Nonlinear Analysis, vol. 8, (1996), 197-203.

[67] T. Zamfirescu, Fix point theorems in metric spaces, Arch. Math., vol. 23, (1972), 292-298

[68] U. Kohlenbach, Some logical metatheorems with applications in functional analysis, Trans. Amer. Math. Soc., vol. 357, (2005), 89-128.

[69] V. Berinde, Some remarks on a fixed point theorem for Ciric-type almost contractions, Carpathian J. Math., vol. 25, no. 2, (2009), 157-162.

[70] V. Berinde, On the convergence of Mann iteration for a class of quasi-contractive operators, North University of Baia Mare,Preprint, (2003).

[71] V. Berinde, on the convergence of the Ishikawa iteration in the class of quasicontractive operators, Acta Math. Univ. Comenianae, vol. 73, no. 1, (2004), 119-126. 
[72] V. Berinde, A convergence theorem for Mann iteration in the class of Zamfirescu operators, Analele Universitatic de vest, Timisoara, Seria Mathematica-Informatica, vol. 45, no. 1, (2007), 33-44.

[73] V. Berinde, Iterative approximation of fixed points, Springer-Verlog Berlin Heidelberg, (2007).

[74] W.G. Doston, Fixed points of quasi-nonexpansive mapping, J. Austral. Math. Soc., vol. 13, (1972), 167-170.

[75] W.A. Kirk, Krasnoselskij's iteration processes in hyperbolic space, Numerical functional Analysis and optimization, vol. 4, (1982), 371-381.

[76] W.A. Kirk, An abstract fixed point theorem for nonexpansive mappings, Proc. Amer. Math. Soc., vol. 82, (1981), 640-642.

[77] W.A. Kirk, Fixed point theory for nonexpansive mappings II. Contemporary Math., vol. 18, (1983), 121-140.

[78] W. Takahashi, A convexity in metric space and nonexpansive mappings, I, Kodai Math. Sem. Rep., vol. 22, (1970), 142-149.

[79] W. Kirk and B. Panyanak, A concept of convergence in geodesic spaces, Nonlinear Anal., vol. 68, (2008), 3689-3696.

[80] W. R. Mann, Mean value methods in iteration, Proc. Amer. Math. Soc., vol. 44, (1953), 506-510.

[81] W. Phuegrattana and S. Suantai, On the rate of convergence of Mann, Ishikawa, Noor and SP iterations for continuous function on an arbitrary interval, Journal of Computational and Applied Mathematics, vol. 235, (2011), 3006-3014.

[82] X. Zhiqun,L.Guiwen and B. E. Rhoades, On Equivalence of some iterations convergence for QuasiContraction maps in convex metric spaces, Fixed Point Theory and Applications, vol. 2010, (2010), 1-10.

[83] Y. X. Tian and Chun-de Yang, Convergence theorems of three-step iterative scheme for a finite family of uniformly Quasi-Lipschitzian mappings in Convex metric spaces, Fixed Point Theory and Applications, vol. 2009, (2009), 1-12.

[84] Y. X. Tian, Convergence of an Ishikawa type Iterative scheme for asymptotically quasi- nonexpansive mapping. Computer and Mathematics with Applications, vol. 49, (2005), 1905-1912.

[85] Ya. I. Alber and S. Guwrre-Delabriere, Principles of weakly contractive maps in Hilbert spaces, new results in operator theory, Advances and Appl. Birkhauser Verlag, Basel, vol. 98, (1976), 7-22.

[86] Y. Xu, Ishikawa and Mann iteration process with errors for nonlinear strongly accretive operator equations, J. Math. Anal. Appl., vol. 224, (1998), 91-101.

[87] Z. Opial, Weak convergence of the sequence of successive approximation for nonexpansive mapping, Bull. Amer. Math. Soc., vol. 73, (1967), 591-597. 